\title{
Prediction of Part Distortion in Die Casting
}

\author{
DE-FC07-97ID13577 \\ Submitted to \\ Department of Energy
}

\author{
By \\ R. Allen Miller
}

February 12, 2002

The Ohio State University

210 Baker Systems Building

1917 Neil Avenue

Columbus, OH 43210 


\section{Table of Contents}

Table of Contents .........................................................................................................

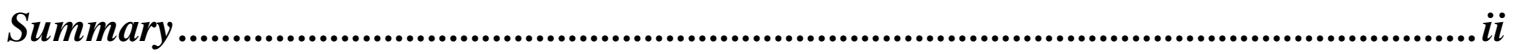

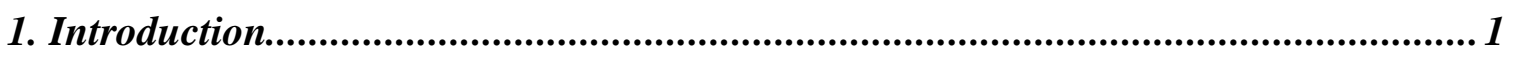

2. Problem Definition …………………......................................................................... 2

3. Model Description …………………................................................................................ 7

3.1 Model Assumptions ................................................................................................................ 7

3.2 Casting/Die Interaction ....................................................................................................8

3.3 Material Definition ...................................................................................................... 11

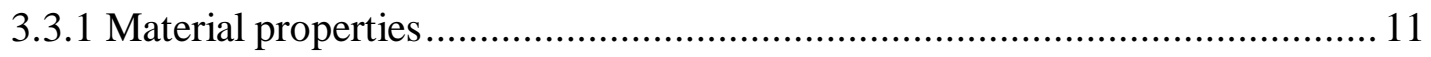

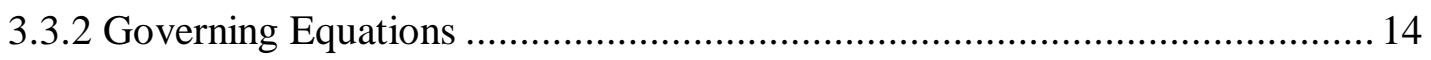

3.4 Finite Element Analysis................................................................................................ 17

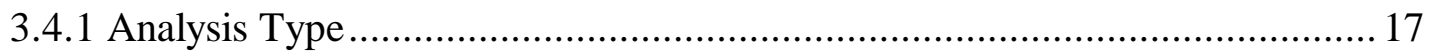

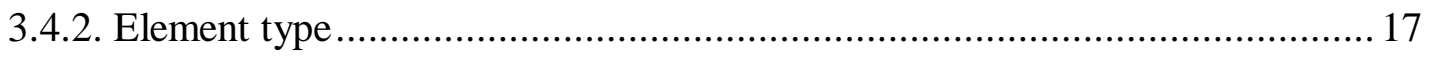

3.5 Model Application .................................................................................................................... 18

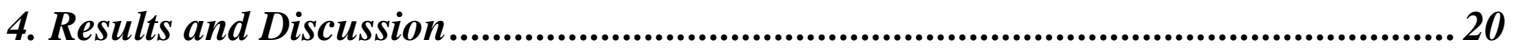

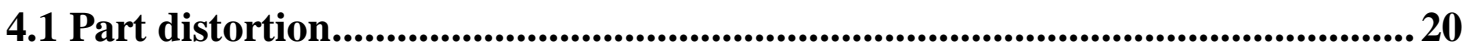

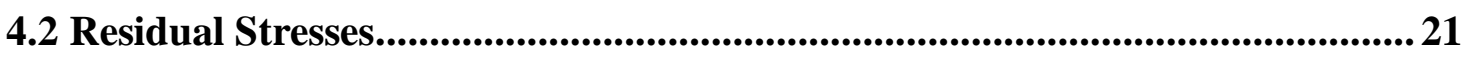

4.3 Air Gap ...................................................................................................................... 25

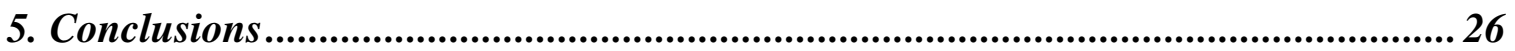

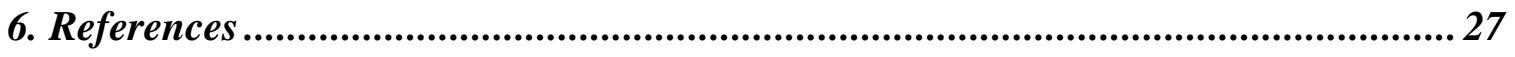




\section{Summary}

The goal of this research was to predict the part deformation and residual stresses after ejection from the die and cooling to room temperature. A finite element model was built to achieve this goal and several modeling techniques were investigated throughout this research.

Die-casting is a very complex process and the researchers are faced with a large number of hard to solve physical problems when modeling the process. Several assumptions are made in our simulation model. The first significant assumption is the instantaneous cavity filling. This means that the cavity filling stage is not considered in our model. Considering the cavity filling stage increases the modeling complexity as a result of different flow patterns expected in the shot sleeve, gate, runner and different cavity features. The flow of gas from the cavity through the vents is another problem that is ignored in our model as a result of this assumption.

Our second assumption is that the cast metal has uniform temperature distribution inside the cavity, at the starting point of simulation. This temperature is assumed to be over liquidus limit, i.e. the solid fraction is $0.0 \%$ of the cast metal.

The third assumption is due to ABAQUS (commercial software used in this research) limitations. ABAQUS cannot deal with multi-phase models; therefore we use solid elements to define the casting instead of multi-phase (liquid/solid) elements. Liquid elements can carry the hydrostatic pressure from the shot sleeve and apply it on the cavity surfaces, while the solid elements do not have this capability. To compensate for this assumption we add the cavity pressure as a boundary condition and apply it on the cavity surface separately from the part. Another issue with this assumption is that, liquid casting can follow the cavity shape when it distorts. With the use of solid elements to represent the casting during its liquid state, it loses this capability to follow the cavity. Several techniques were tested to overcome this problem. Decreasing the modulus of elasticity of the casting at the beginning is one of them, but results still are not as good as expected. 
The last assumption is that all the applied loads are static. This includes clamping and cavity pressure. Although the motion of the machine parts causes some inertia and hence some dynamic loads, modeling it is very complicated and beyond the scope of this research.

The results from research show the importance of some modeling factors used to represent the die casting process in a simulation. The most important factor is the material model used to describe the casting. In this research three material models were investigated. These are elastic, elasto-plastic and elasto-viscoplastic. The results showed very significant difference in the predicted distortion and residual stresses among the three models. The plasticity and creep allow the casting to relax and release some of its residual stresses. In fact, considering the creep properties in the model results in much higher computational time, and compromise arises between the accuracy and tractability of the model. The decision should be made in particular for each case.

The research shows also the lack of data for A1380. This includes the creep properties, plasticity properties; yield strength and modulus of elasticity at high temperatures. Using the exact properties in the model is very important in order to get the required accurate results.

The results showed also that the criteria to model some of the machine components, namely, tie bars and toggle system do not affect the results. The researcher might select the best method to fit his finite element package and to allow results as fast as possible.

There is no way to get reliable results from the simulation unless we can modify our modeling techniques to overcome some of the limitations. The first limitation that we need to overcome is the one-phase simulation. The die casting process is a multi-phase process and we need to consider this in our model. We need to consider the liquid, solid and probably the mushy zone phases. Also we need to compare our simulation results with a well-defined experimental set up. 


\section{Introduction}

A quantitative understanding of the stress distribution and the deformation pattern of parts during casting process will result in closer tolerances to the part design specification, a better die design and eventually to more productivity and cost saving. To achieve these objectives the casting and the dies have to be studied together as an integrated system. This will enable practitioners to more accurately predict the deformation of the part in the final form using analytical tools.

The study of deformation and stress in a solidifying body presents a monumental challenge from multi-physics involved to numerical solution algorithms. The solidification process needs an accurate description of the thermo-mechanical behavior of the solidifying body. The material, mechanical and thermal, properties of the solidifying part are highly temperature dependent. This temperature dependency will force simultaneous solution of the temperature and stress equations. Also temperature dependency of the properties will results in a set of non-linear systems. The stress relaxation and creep behavior during solidification will drastically alter the deformation patterns and residual stresses in a solidifying body and subsequent cooling. Therefore an accurate model of the creep-relaxation is required to predict the stress and deformation of casting in the final form.

During solidification phase the casting will shrink. The inserts will experience a cyclic thermal load and it will grow from its initial size at room temperature. Gaps can form between the casting and the inserts. An approximate but representative model of the gap heat transfer is essential for correct prediction of the heat loss to the inserts. The heat loss to the inserts wall will decrease rapidly as the gap opening increases. The gap locations and its form may differ from cycle to cycle, until a steady state operating conditions is reached.

The casting and die cavity geometry will limit the casting movement and will influence to a large degree the final casting deformation and stresses. The casting is not free to move or slide on the inserts walls. The casting will interact mechanically with 
inserts walls due to friction. The mechanical interaction of the casting and inserts needs to be included in the simulation through contacting surfaces of casting and inserts. The frictional effects will increase the system non-linearity and will drastically increase the computational time.

The clamping load will be applied to the dies and inserts; this load will deform the cavity shape. When the cavity is filled, the intensification pressure is applied to the part. This hydrostatic load will distort the cavity further more and will relocate the molten metal in the die cavity. Therefore, the die cavity will be filled in its deformed shape. As the casting shrinks, it solidifies and in turn the die will react to the casting shrinkage instantaneously. Due to interaction of the inserts and the casting, the final casting shape and its deformation cannot be predicted if only, the casting is considered in the simulation. Therefore, it is imperative to include both the casting and inserts in the analysis under the thermal and mechanical loads and contact interaction between them. This will lead to increased model size and computational resources needed. It is also known from previous experience that the effect of the machine parts on the whole processes is very significant. Therefore the machine components should be included in the simulation, particularly, dies, platens, toggle system, and cooling lines must be modeled with their interactions with the part and the inserts. This will increase model size substantially, its complexity and hence will increase dramatically the required computational powers.

\section{Problem Definition}

The Foundarymen's handbook [1] defines the casting distortion as "If the casting strains are great enough to force the casting from it's intended shape, it is said to be distorted. This distortion is sometimes called warping". Figure1 shows a distorted casting [2]. The strains that may cause distortion are being developed through the casting upon the beginning of solidification.

The common reason for developing these strains in the casting is the variation of

cooling rates between its different sections [3,4]. Castings that suffer these variations 
may be subjected to cracks, distortion and structural weaknesses [3]. This variation in cooling rates may be due to casting design or casting process. Thin sections will cool more rapidly than the thick ones. This will result in the thin sections contracting ahead of the thick ones [3]. Sometimes contraction may take place in some sections and expansion in others [3]. This is due to the phase change. Figure2-a shows a casting of a simple shape, consisting of three parallel members equal in length and connected together in their ends by rigid cross members of equal length [3]. This casting will end as seen in Fig. 2-b with the middle member distorted. This is because the outer members will cool faster than the center one [3].

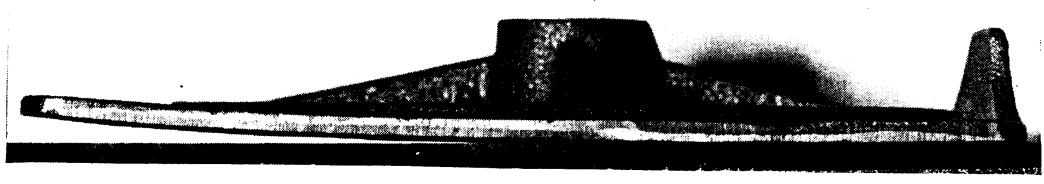

Figure 1 Distorted Part [2]

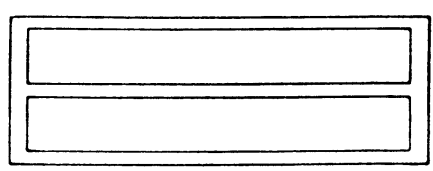

Figure 2-a [3]

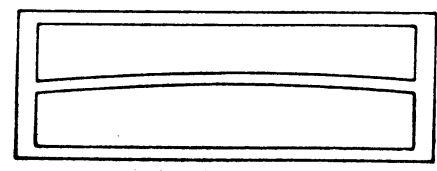

Figure 2-b [3]

A solidifying material suffers deformation in a completely different way from that of a standard solid body [5]. This difference is due to two reasons. The first reason is the characteristics of the liquid, which displaces without causing stresses [5]. Secondly, the formation of stresses in the solidifying body starts immediately after solidification, and it is never in a stress-free state [5]. 
Figure 3 shows a simplified sequence of steps, which lead to the typical stress and distortion profiles [5,6]. The first step shows two thin liquid layers of the casting [i.e. outer layer and inner layer]. The outer layer solidifies first, as expected, without generating significant stresses, unless it is stacked to the mold, which is not our case here. This stress free solidification is due to the relatively freedom of this layer to shrink towards the inner layer and displaces some of the liquid above it [5].

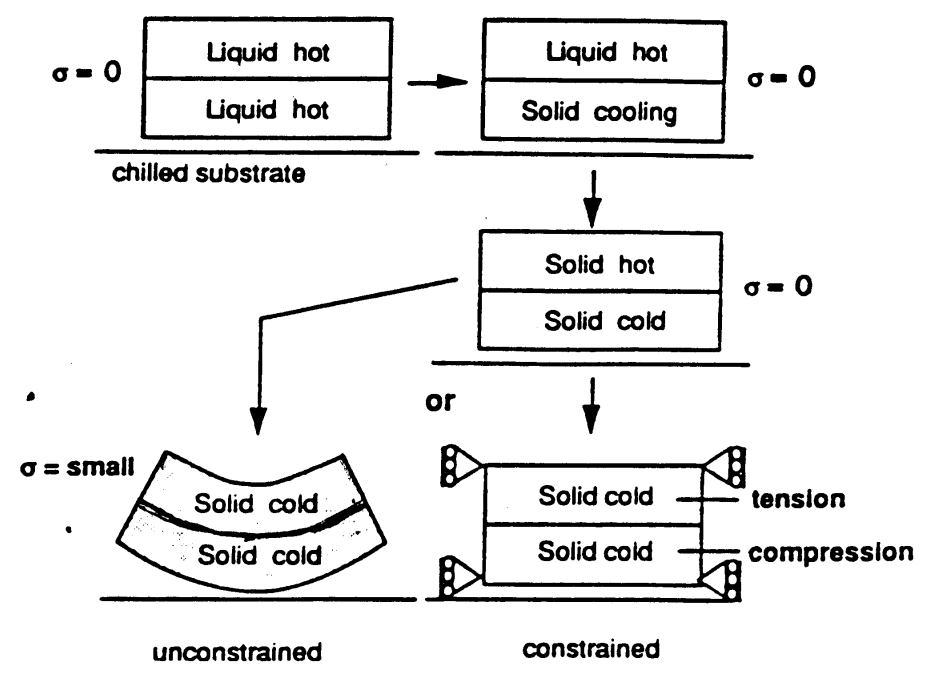

Figure 3 Mechanical behavior of a solidifying shell [5]

When the second layer solidifies, it also solidifies stress free. The final step shows that the inner layer tries to shrink, upon cooling, opposite to the mold face (chilled substrate), and there is no liquid to displace, thus results in the distortion shown [5]. This is repeated as later layer solidifies. If the casting is restricted as shown, the distortion is prevented but the stresses in the shell will be very high [5].

To have a sound casting a lot of allowances must be added to the pattern/mold design to compensate for the difference between the pattern/mold shape and the resultant casting. Shrinkage allowance and machining allowance are typical examples. For those castings that are subjected to distortion more than the allowable, distortion allowance must be added. This allowance is added to the pattern/mold depending on previous experience and/or by "trial and error" for a given alloy, and according to the casting process characteristics. Figure 4 shows a top view of a typical mold shape used to 
produce flat rolling ingots of aluminum alloys using continuous casting [7]. The difference is clear between cross section of the desired ingot, which is rectangular, and the mold shape. This difference is made to compensate for the deformation of the ingot upon cooling [7].

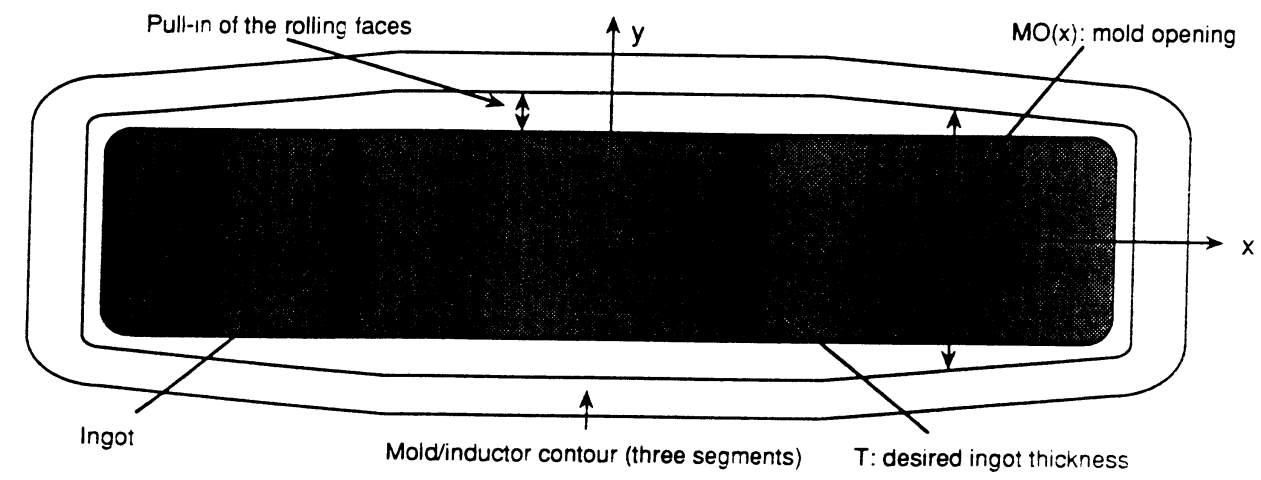

Figure 4 Schematic top view of the mold required to produce flat rolling ingots [7]

In die casting processes the part distortion criteria is more complicated than continuous or sand casting. This is mainly because of the enormous forces involved which may reach several thousands tons. These huge forces distort the die (the mold) and hence complicate the part distortion phenomena.

Figure 5 shows the operation sequence in die casting process. The machine is first clamped, the molten metal is injected and then the intensification is added. This sequence leads to the fact that the die is distorted first due to the clamping load. The molten metal is then injected and intensified. Since the metal at this time is mostly liquid it is capable to transform the hydrostatic pressure from the shot sleeve to the cavity surfaces, which leads to additional die distortion. During solidification and cooling the die is distorted again due to the thermal loads. Figures 6 shows this die distortion sequence in a simplified cavity shape. 


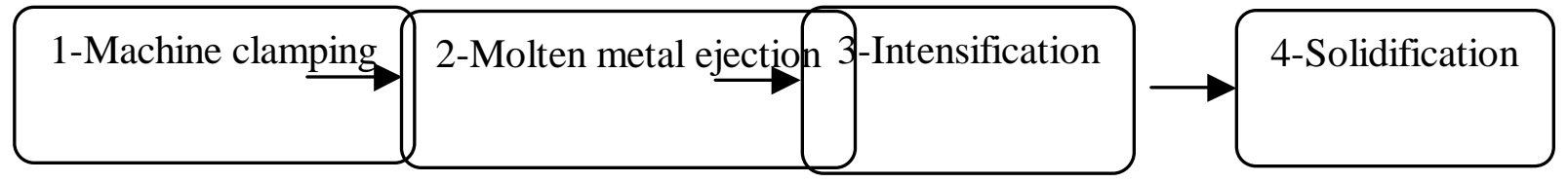

Figure 5 The die casting process sequence

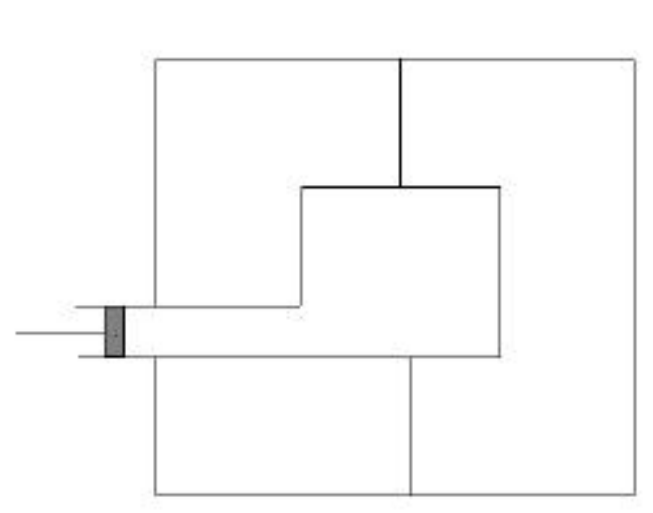

Idle machine
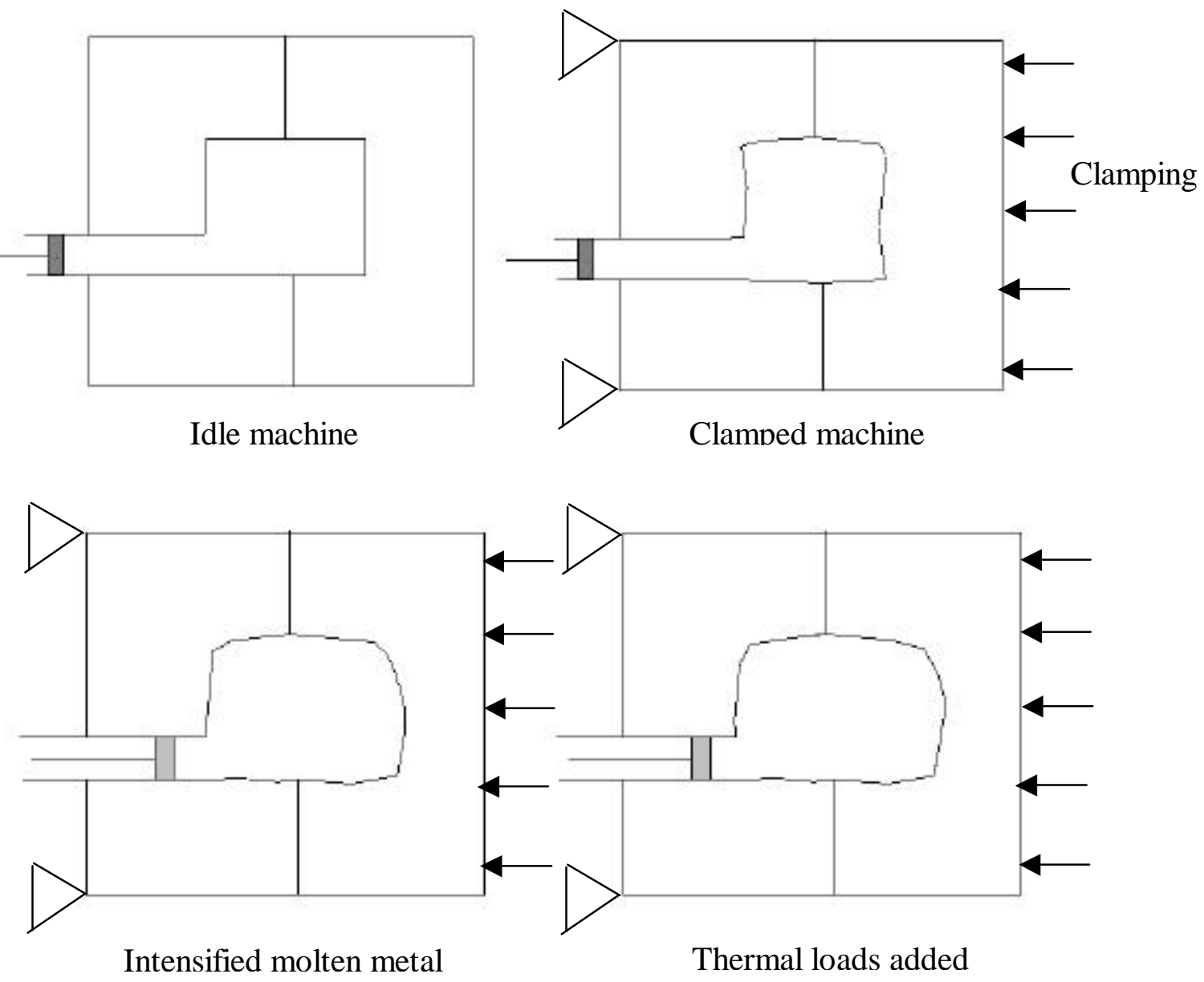

Figure 6 Die casting distortion sequence 


\section{Model Description}

\subsection{Model Assumptions}

Die-casting is a very complex process and the researchers are faced with a large number of hard to solve physical problems when tackling the modeling process. Due to these challenges it is deemed necessary to start the modeling simulation with some assumptions. Although these assumptions may affect the results, it is only way that a researcher can get a representative model for the die casting process. Usually a researcher concerns only with one particular area of die casting processes and ignores, or assumes, the other aspects. These assumptions are not only due to the complexity of the physical phenomena that are involved, but also due to the limitations of the software that may be used, this includes both finite elements and finite difference packages presently available. Some of this software is designed particularly for die-casting and some others are general-purpose ones. In the first category the assumptions are already built in the software to fit the particular end user. The user gets the results with these assumptions in mind. In the latter category, the user is free to manipulate his assumptions depending on his/her thoughts and goals. One thing to keep in mind is that, even for the generalpurpose packages, some assumptions are buried within the package code itself. In our research a general-purpose finite element package (ABAQUS) is used to simulate the die casting process.

Several assumptions are made in our simulation model, which aims to predict the casting distortion and residual stresses after complete cooling. The first significant assumption is the instantaneous cavity filling. This means that the cavity filling stage is not considered in our model. Considering the cavity filling stage increases the modeling complexity as a result of different flow patterns expected in the shot sleeve, gate, runner and different cavity features [8]. The flow of gas from the cavity through the vents is another problem that is ignored in our model as a result of this assumption.

Our second assumption is that the casted metal has uniform temperature distribution inside the cavity, at the starting point of simulation. This temperature is assumed to be over liquidus limit, i.e. the solid fraction is $0.0 \%$ of the casted metal. 
The third assumption is due to ABAQUS limitations. ABAQUS cannot deal with multi-phase models; therefore we use solid elements to define the casting instead of

multi-phase (liquid/solid) elements. Liquid elements can carry the hydrostatic pressure from the shot sleeve and apply it on the cavity surfaces, while the solid elements do not have this capability. To compensate for this assumption we add the cavity pressure as a boundary condition and apply it on the cavity surface separately from the part. Another issue with this assumption is that, liquid casting can follow the cavity shape when it distorts. With the use of solid elements to represent the casting during its liquid state, it loses this capability to follow the cavity. Several techniques were tested to overcome this problem. Decreasing the modulus of elasticity of the casting at the beginning is one of them, but results still are not as good as expected.

The last assumption is that all the applied loads are static. This includes clamping and cavity pressure. Although the motion of the machine parts causes some inertia and hence some dynamic loads, modeling it is very complicated and beyond the scope of this research.

\subsection{Casting/Die Interaction}

The effect of die/casting interaction on the final shape of the part and its residual stresses is very significant [9-10]. While inside the die the casting may not be free to distort against the die surface, leading to residual stresses build up. This alters the stress history of the part and hence, the final part distortion and stresses are expected to change. Also as mentioned before the shape of the die changes due to cavity pressure, clamping loads and thermal expansion. The final shape of the part is a function of the die shape. Figure 7 shows the effect of mold distortion on the casting shape [9]. 


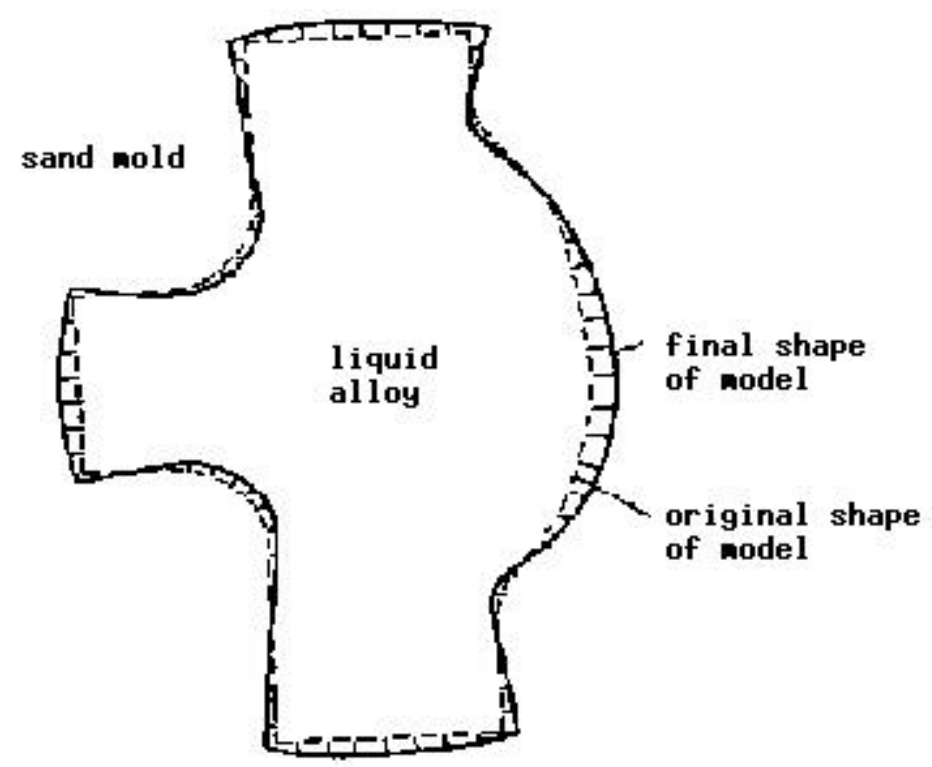

Figure 7 The effect of mold distortion on casting shape [9]

Another important issue is the contact between the casting and the die. Theoretically the casting/die is assumed to be in perfect contact at the beginning of the simulation. As the molten metal solidifies, a gap may form between them. The gap width and position affect the heat transfer coefficient between the casting and the die, and hence the temperature history of the casting. The gap position and width cannot pre-determined by part geometry even for a simple casting shape, and hence it should be predicted from the simulation. Figure 8 shows the decrease of the heat transfer coefficient in permanent mole casting versus time. This decrease is mainly due to gap formation between the casting and the mold [9]. Figure 9 shows the position of air gaps formed in sand casting for simple part geometry [9]. Very limited values are available about the effect of gap on the heat transfer coefficient between casting and die in die-casting. However we could assume some values depending on researches in permanent mold casting [9-11], as shown in Table 1 . The heat transfer coefficient is assumed to change linearly between the given gaps widths. 


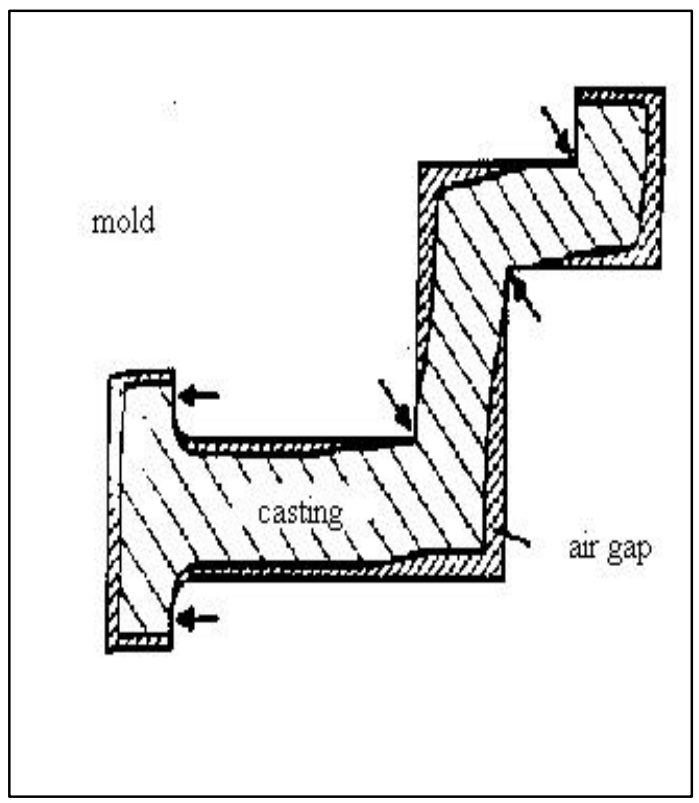

Figure 9 Positions of air gaps in sand casting [9]

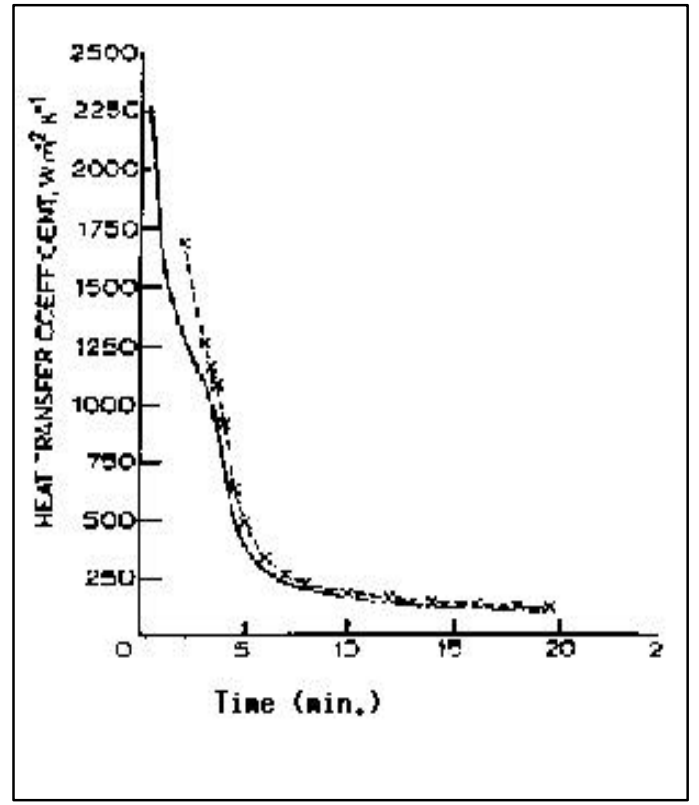

Figure 8 Heat transfer coefficient vs. time in permanent mold casting

\begin{tabular}{|c|c|}
\hline $\begin{array}{c}\text { Heat transfer coefficient } \\
\left(\mathrm{W} / \mathrm{m}^{2} \mathrm{~K}\right)\end{array}$ & $\begin{array}{c}\text { Air Gap Width } \\
(\mathrm{m})\end{array}$ \\
\hline 10000 & 0.000 \\
\hline 8000 & $2.0 \mathrm{E}-7$ \\
\hline 6000 & $3.5 \mathrm{E}-7$ \\
\hline 4000 & $5.0 \mathrm{E}-7$ \\
\hline 2000 & $7.0 \mathrm{E}-7$ \\
\hline 1000 & $12.0 \mathrm{E}-7$ \\
\hline
\end{tabular}

Table 1 Values of heat transfer coefficient versus gap width

The friction coefficient between the casting and the dies may have some effect on the part/die interaction and therefore on the stress history of the part. A friction value of 0.3 is used in our model. 


\subsection{Material Definition}

\subsubsection{Material properties}

Accurate definition of material properties in the model is one of the important keys for reliable results. This includes both the physical and mechanical properties. For the casting material (i.e. aluminum alloy 380) most of properties are temperature dependent. This temperature dependency was considered in our model. The main problem was the unavailability of material properties data for Al380 at high temperatures (over $200^{\circ} \mathrm{C}$ ). For this case we were able to use another aluminum alloy, which is close to Al 380 in composition. This alloy contains $7.5 \% \mathrm{Si} \& .4 \% \mathrm{Mg}$ and $92.1 \% \mathrm{Al}$, where the composition of Al380 is shown in Table 2 [12].

\begin{tabular}{|c|c|c|c|c|l|}
\hline Component & Wt. \% & Component & Wt. \% & Component & Wt. \% \\
\hline $\mathrm{Al}$ & $80.05-89.5$ & $\mathrm{Mg}$ & $\operatorname{Max} 0.1$ & $\mathrm{Si}$ & $7.5-9.5$ \\
\hline $\mathrm{Cu}$ & $3-4$ & $\mathrm{Mn}$ & $\operatorname{Max} 0.5$ & $\mathrm{Sn}$ & Max. 0.35 \\
\hline $\mathrm{Fe}$ & $\mathrm{Max} 2$ & $\mathrm{Ni}$ & Max 0.5 & $\mathrm{Zn}$ & Max. 3 \\
\hline
\end{tabular}

Table 2 The composition of aluminum alloy 380

The physical properties used in the model are illustrated in the next figures. Figures 10 and 11 show the density and thermal conductivity of the aluminum alloy 380 versus temperature, respectively [13]. Figures 12 and 13 show the specific heat and thermal expansion coefficient for the aluminum alloy $(7.5 \% \mathrm{Si}, 0.4 \% \mathrm{Mg}$.) versus temperature respectively [14]. 


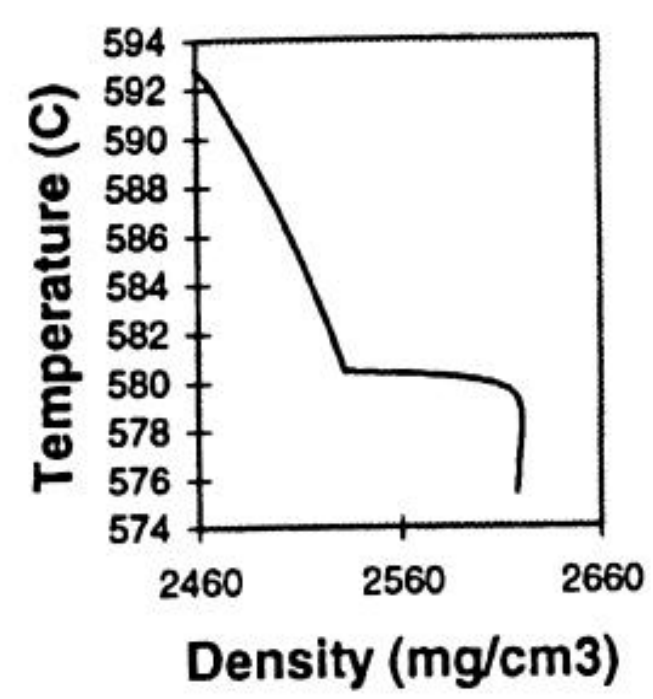

Figure 10 Density of aluminum alloy 380 versus temperature [13]

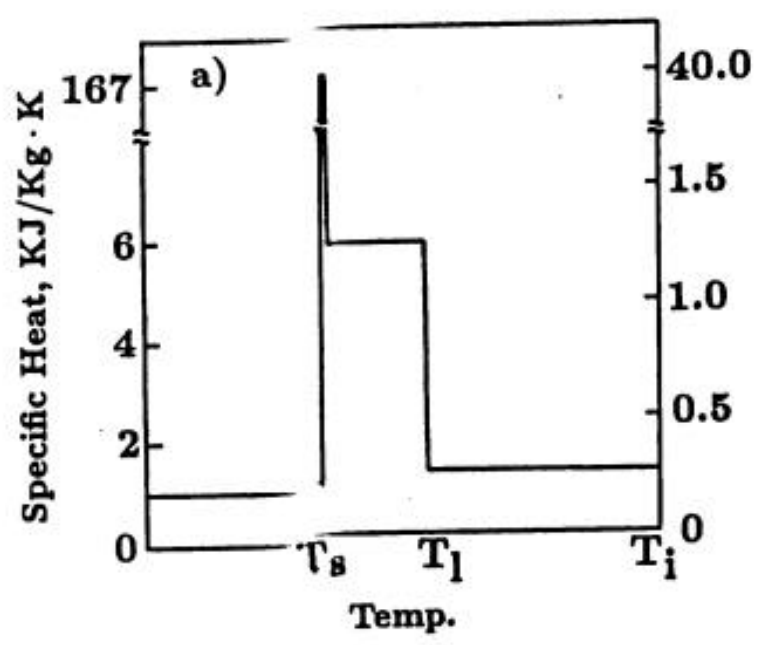

Figure 12 Specific heat of aluminum alloy $(7.5 \% \mathrm{Si}, 0.4 \% \mathrm{Mg})$ versus temperature [14]

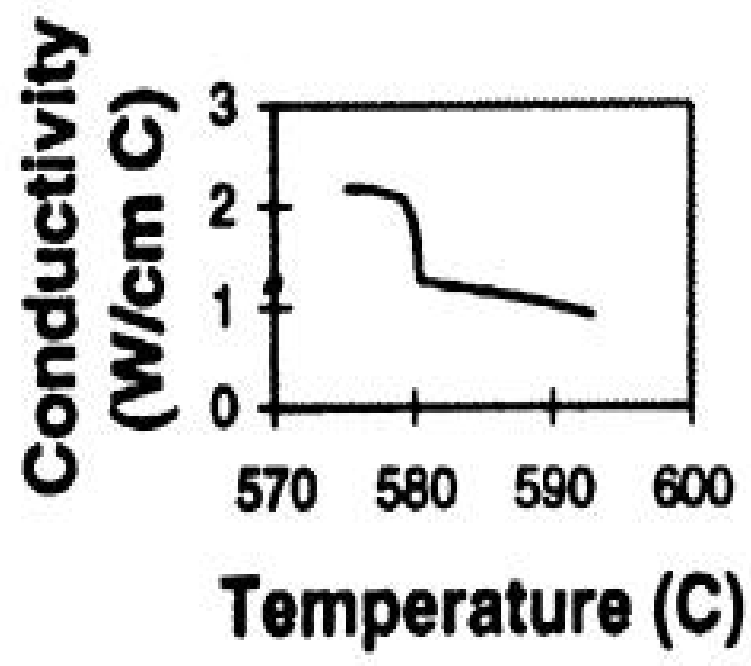

Figure 11 Thermal conductivity of aluminum alloy 380 versus temperature [13]

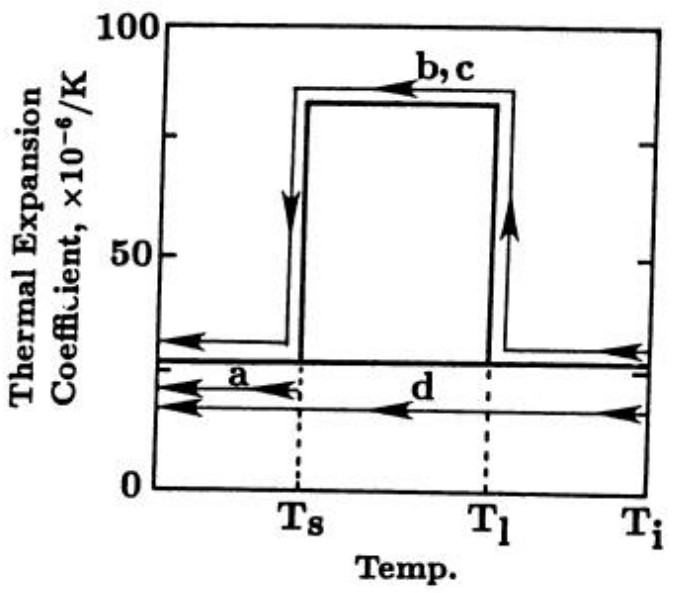

Figure 13 Thermal expansion Coefficient of aluminum alloy $(7.5 \% \mathrm{Si}$, $0.4 \% \mathrm{Mg}$ ) versus temperature [14]

Mechanical properties are available for aluminum alloy $\mathrm{Al} 380$ up to $200^{\circ} \mathrm{C}$ [15]. Figure 14 shows the stress-strain curve for Al380 at different temperatures. For temperatures over $200^{\circ} \mathrm{C}$ we used aluminum alloy $(7.5 \% \mathrm{Si}, 0.4 \% \mathrm{Mg})$, properties shown in Figure 15 [14]. Creep properties for aluminum alloy 380 are not available, so we used the creep properties for pure aluminum. 


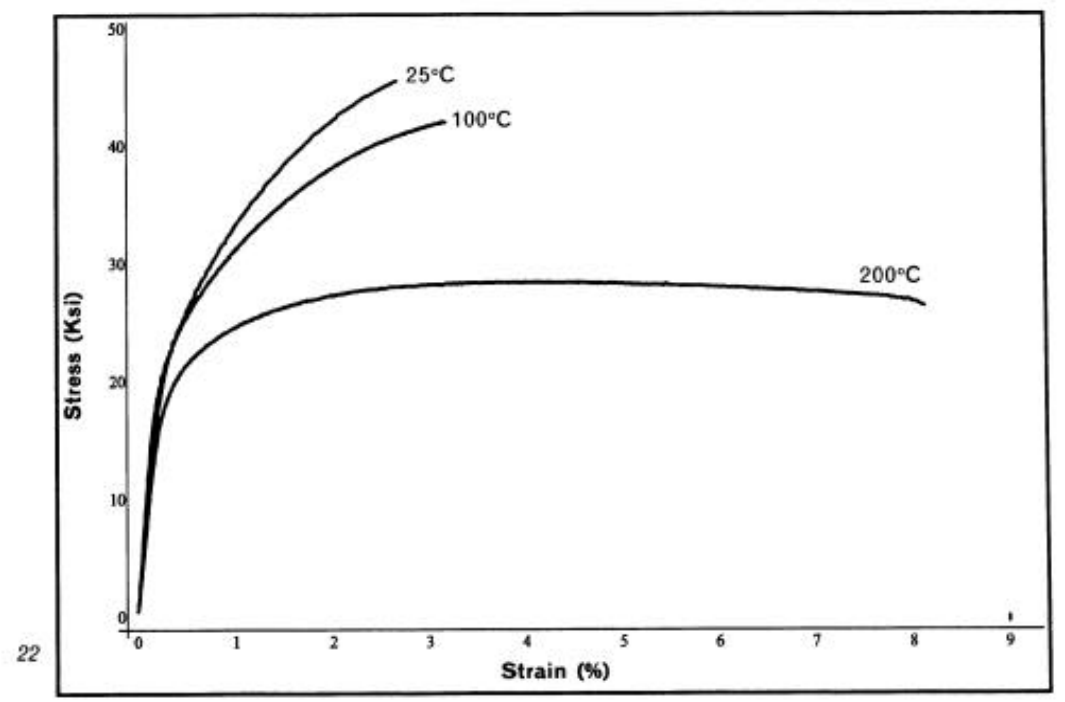

Figure 14 Stress-strain curve for aluminum alloy 380 at different temperatures [15]

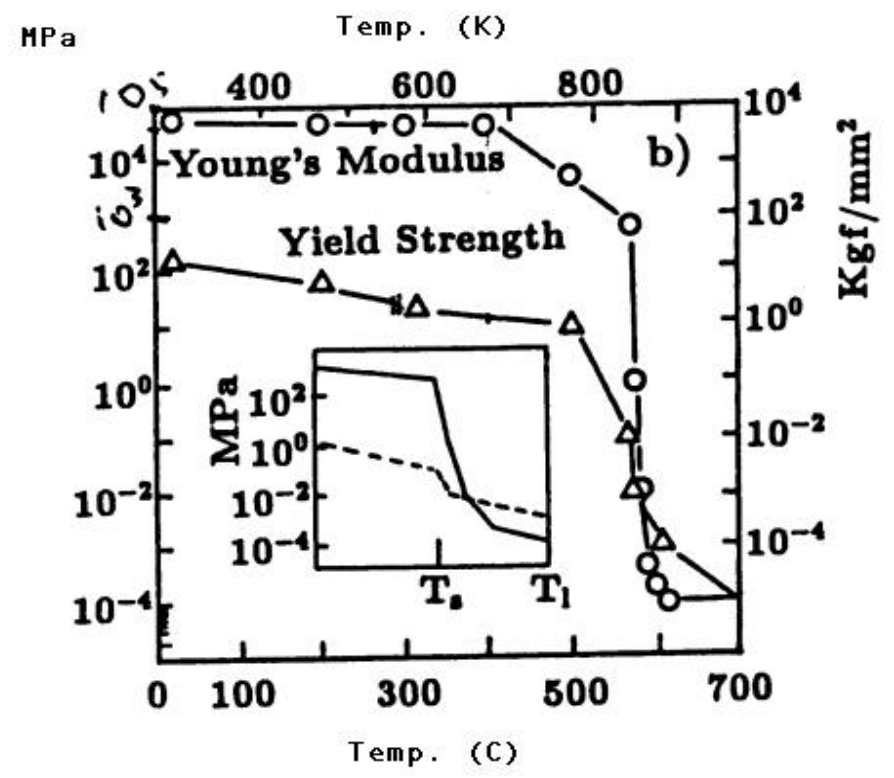

Figure 15 Yield strength and modulus of elasticity of al. alloy $(7.5 \% \mathrm{Si}, 0.4 \% \mathrm{Mg})$ versus temperature [14]

The values shown in Figure 15 for yield strength and modulus of elasticity cannot be used exactly in the model. The very low values at high temperatures cause convergence problems in the finite element analysis. Table 3 shows the values that actually used in the model. 


\begin{tabular}{|l|l|l|l|}
\hline \multicolumn{1}{|c|}{$\begin{array}{c}\text { Temperature } \\
\left({ }^{\circ} \mathrm{C}\right)\end{array}$} & \multicolumn{1}{|c|}{$\begin{array}{c}\text { Yield Strength } \\
(\mathrm{Mpa})\end{array}$} & \multicolumn{1}{c|}{$\begin{array}{c}\text { Modulus of Elasticity } \\
(\mathrm{Mpa})\end{array}$} & \multicolumn{1}{c|}{ Poisson Ratio } \\
\hline 25 & 159 & 70000 & .33 \\
\hline 100 & 159 & 70000 & .355 \\
\hline 200 & 130 & 65000 & .37 \\
\hline 300 & 80 & 60000 & .38 \\
\hline 400 & 40 & 50000 & .41 \\
\hline 500 & 20 & 10000 & .42 \\
\hline 600 & 20 & 30 & .43 \\
\hline
\end{tabular}

Table 3 Values of mechanical properties used in the model

\subsubsection{Governing Equations}

The casting model simulation involves thermal and stress analysis. The thermal analysis requires solving the energy balance equation (1). This equation must be solved for the casting and the mold to find the temperature history at every point in the casting, $\mathrm{T}[\mathrm{x}, \mathrm{y}, \mathrm{z}, \mathrm{t}]$.

$\frac{\partial}{\partial x}\left(K_{x} \frac{\partial T}{\partial x}\right)+\frac{\partial}{\partial y}\left(K_{y} \frac{\partial T}{\partial y}\right)+\frac{\partial}{\partial z}\left(K_{z} \frac{\partial T}{\partial z}\right)+Q=\rho C_{p}\left(\frac{\partial T}{\partial t}+V_{x} \frac{\partial T}{\partial x}+V_{y} \frac{\partial T}{\partial y}+V_{z} \frac{\partial T}{\partial z}\right)$

Where:

$\mathrm{K}=$ Thermal conductivity

$\mathrm{C}_{\mathrm{p}} \quad=$ Specific heat

$\rho \quad=$ Density

Q = Heat source (including the latent heat)

$\mathrm{V}_{\mathrm{x}} \quad=$ Flow velocity in $\mathrm{X}$ direction

$\mathrm{V}_{\mathrm{y}} \quad=$ Flow velocity in $\mathrm{Y}$ direction

$\mathrm{V}_{\mathrm{z}} \quad=$ Flow velocity in $\mathrm{Z}$ direction 
According to our assumptions, the molten metal flow is not considered; therefore all velocity terms are equal to "zero". We also assume an isotropic material; i.e. material properties are not position dependent. It is assumed, in the simulation the latent heat is released uniformly between solidus and liquidus temperatures. Under these assumptions equation 1 is simplified to equation (2):

$$
\frac{\partial^{2} T}{\partial x^{2}}+\frac{\partial^{2} T}{\partial y^{2}}+\frac{\partial^{2} T}{\partial z^{2}}+Q=\rho C_{p} \frac{\partial T}{\partial t}
$$

The previous equations take care of the thermal analysis. For the stress analysis there are three types of equations that must be solved [5,6]. First, the mechanical equilibrium equations, which relates the incremental applied forces to the resulted incremental stresses, second, the compatibility equations, which govern the incremental strains with incremental displacements and third, the constitutive equations that relate the incremental stresses and incremental strains. The first two equations are given by equations $3 \& 4$ respectively.

$$
\begin{aligned}
& {[\mathrm{L}]^{\mathrm{T}} \Delta \sigma=\mathrm{F}} \\
& \Delta \varepsilon=[\mathrm{L}] \Delta \mathrm{u}
\end{aligned}
$$

Where:

$$
[\mathbf{L}]=\left[\begin{array}{ccc}
\partial / \partial \mathrm{x} & 0 & 0 \\
0 & \partial / \partial \mathrm{y} & 0 \\
0 & 0 & \partial / \partial \mathrm{z} \\
\partial / \partial \mathrm{y} & \partial / \partial \mathrm{x} & 0 \\
0 & \partial / \partial \mathrm{z} & \partial / \partial \mathrm{y} \\
\partial / \partial \mathrm{z} & 0 & \partial / \partial \mathrm{x}
\end{array}\right]
$$

$$
\begin{array}{ll}
\Delta \sigma=\left\{\Delta \sigma_{\mathrm{x}}, \Delta \sigma_{\mathrm{y}}, \Delta \sigma_{\mathrm{z}}, \Delta \tau_{\mathrm{xy}}, \Delta \tau_{\mathrm{yz}}, \Delta \tau_{\mathrm{zx}}\right\} & \text { is the incremental stress. } \\
\Delta \varepsilon=\left\{\Delta \varepsilon_{\mathrm{x}}, \Delta \varepsilon_{\mathrm{y}}, \Delta \varepsilon_{\mathrm{z}}, \Delta \gamma_{\mathrm{xy}}, \Delta \gamma_{\mathrm{yz}}, \Delta \gamma_{\mathrm{zx}}\right\} & \text { is the incremental strain. } \\
\Delta \mathrm{F}=\left\{\Delta \mathrm{F}_{\mathrm{x}}, \Delta \mathrm{F}_{\mathrm{y}}, \Delta_{\mathrm{z}}\right\} & \text { is the external force increments. } \\
\Delta \mathrm{u}=\left\{\Delta \mathrm{u}_{\mathrm{x}}, \Delta \mathrm{u}_{\mathrm{y}}, \Delta \mathrm{u}_{\mathrm{z}}\right\} & \text { is the displacement increments. }
\end{array}
$$


The incremental total strain vector, $\Delta \varepsilon$, is given by the following equation:

$$
\Delta \varepsilon=\Delta \varepsilon_{\mathrm{e}}+\Delta \varepsilon_{\mathrm{t}}+\Delta \varepsilon_{\mathrm{p}}+\Delta \varepsilon_{\mathrm{cr}}
$$

Where:

$\Delta \varepsilon_{\mathrm{e}}=$ the elastic strain increment.

$\Delta \varepsilon_{\mathrm{t}}=$ the thermal strain increment.

$\Delta \varepsilon_{\mathrm{p}}=$ The plastic strain increment.

$\Delta \varepsilon_{\mathrm{cr}}=$ The creep strain increment.

The third type of equations to be solved, i.e. the constitutive equations, depends on the material model. Several material models can be used to describe the behavior of the casting. In our analysis we used three material models. These are elastic, elasticplastic and elastic-plastic with creep. For the elastic-plastic model we used the elastoplastic constitutive equations. To add the creep we used the hyperbolic-sine law constitutive equations. Details for the elasto-plastic and hyperbolic-sine low are beyond the goal of this report and can be found in several references [e.g. 16-17]. For the elastic analysis the constitutive equation is given by equation 6 .

$$
\Delta \sigma=[\mathrm{D}] \varepsilon_{\mathrm{e}}
$$

Where:

$$
[D]=\frac{E}{(1+v)(1-2 v)}\left[\begin{array}{cccccc}
1-v & v & v & 0 & 0 & 0 \\
v & 1-v & v & 0 & 0 & 0 \\
v & v & 1-v & 0 & 0 & 0 \\
0 & 0 & 0 & (1-2 v) / 2 & 0 & 0 \\
0 & 0 & 0 & 0 & (1-2 v) / 2 & 0 \\
0 & 0 & 0 & 0 & 0 & (1-2 v) / 2
\end{array}\right]
$$

$\mathrm{E}=$ modulus of elasticity

$v=$ Poisson ratio 


\subsection{Finite Element Analysis}

\subsubsection{Analysis Type}

The solution of the energy equation to define the temperature history of the casting may be done separately from the stress analysis or simultaneously. The separate solution is called uncoupled (or, sequtionaly coupled), thermal and mechanical analysis together is called coupled (or, simultaniously coupled) analysis.

The coupled analysis "is performed when the mechanical and thermal solutions affect each other strongly and, therefore, must be obtained simultaneously" [16]. In our model the effect of air gap on the heat transfer coefficient between casting and dies and the dependence of material properties on temperature lead to interchangeable effect between thermal and stress analysis. Therefore the coupled analysis is the only option for our simulation model.

\subsubsection{Element type}

Several element types are available for modeling casting processes. Some of them (2D elements) may be suitable for very simple parts, which is not the usual case in diecasting. In our model we use 8-noded 3D brick elements. According to ABAQUS manual [16], brick elements are more reliable than tetrahedral elements, especially in solidification and stress analysis.

The 8-noded brick (hexagonal) element is a linear element that can be used in thermal, mechanical and coupled analysis. In coupled analysis the element has 4 degrees of freedom: three degrees of freedom for the displacement $\left(u_{x}, u_{y}, u_{z}\right)$ and one degree of freedom for temperature $(\mathrm{T})$.

Another element type that we are trying in this project is the hybrid 8-noded brick elements. This element can carry hydrostatic pressure as liquid, although it is a solid element. The problem with this type of element is that it cannot displace as a liquid element does and hence the distortion patterns looks unreasonable. More research is needed for this element type before getting any reliable results. 


\subsection{Model Application}

The simulation model was applied on a test part, as shown in Figure 16. The geometry model included, beside the part, the platens, holder blocks, inserts, cooling lines, toggle system and tie bars. To simplify the model, the toggle system and the tie bars were not explicitly modeled, but were replaced with springs. Figures $17 \& 18$ show the finite element model and the schematic drawing of the die dasting machine respectively.

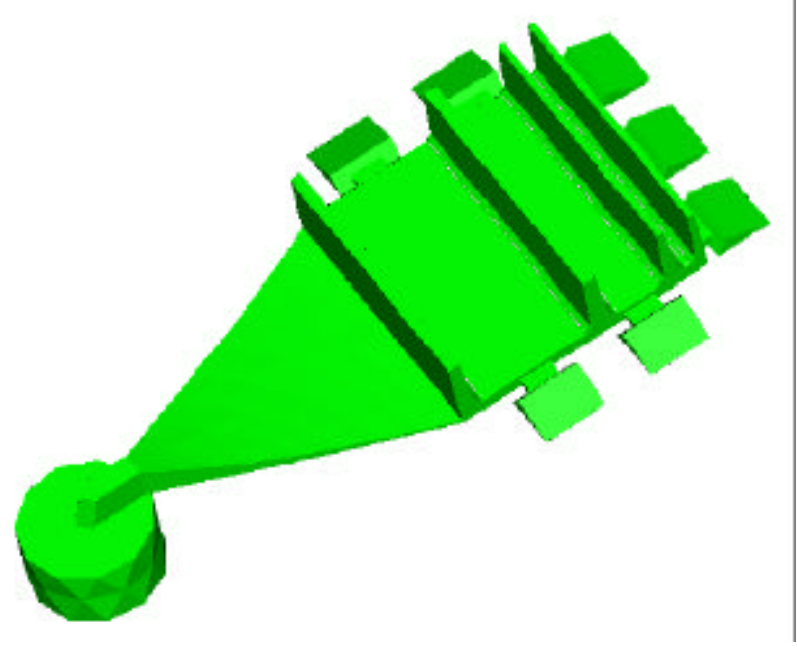

Figure 16 the test part used in the model

- The part dimensions are:

$\begin{array}{lc}\text { Length }= & 250 \mathrm{~mm} \\ \text { Width }= & 100 \mathrm{~mm} \\ \text { Height }= & 50 \mathrm{~mm} \\ \text { Maximum thickness }= & 5 \mathrm{~mm} \\ \text { Minimum thickness }= & 2.5 \mathrm{~mm}\end{array}$

- Other important factors:

Cycle time $=\quad 40$ seconds

Solidification time $=\quad 9$ seconds

Machine capacity $=\quad 250$ tons

Initial casting temperature $=600^{\circ} \mathrm{C}$

Initial inserts temperature $=80^{\circ} \mathrm{C}$ 


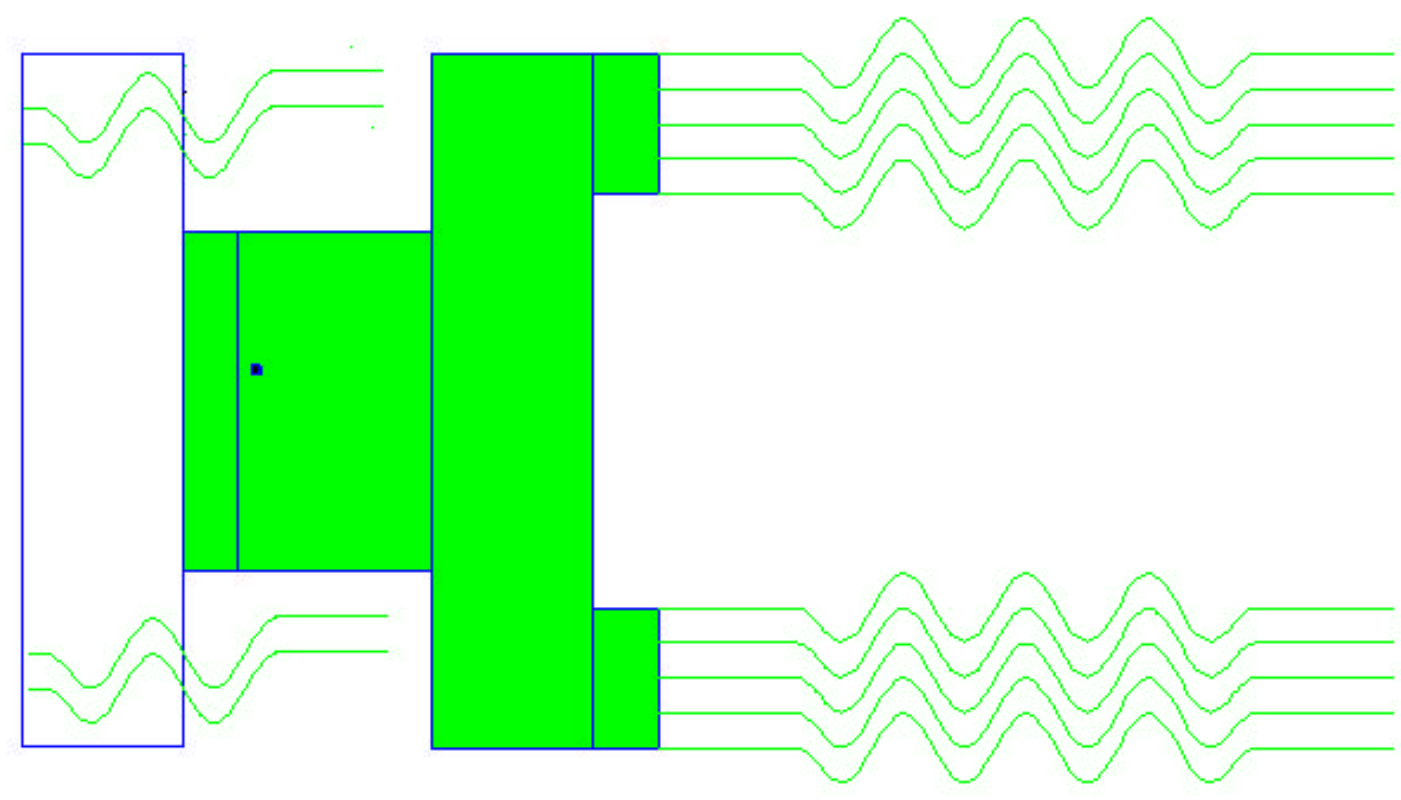

Figure 17 Half model of the die-casting machine

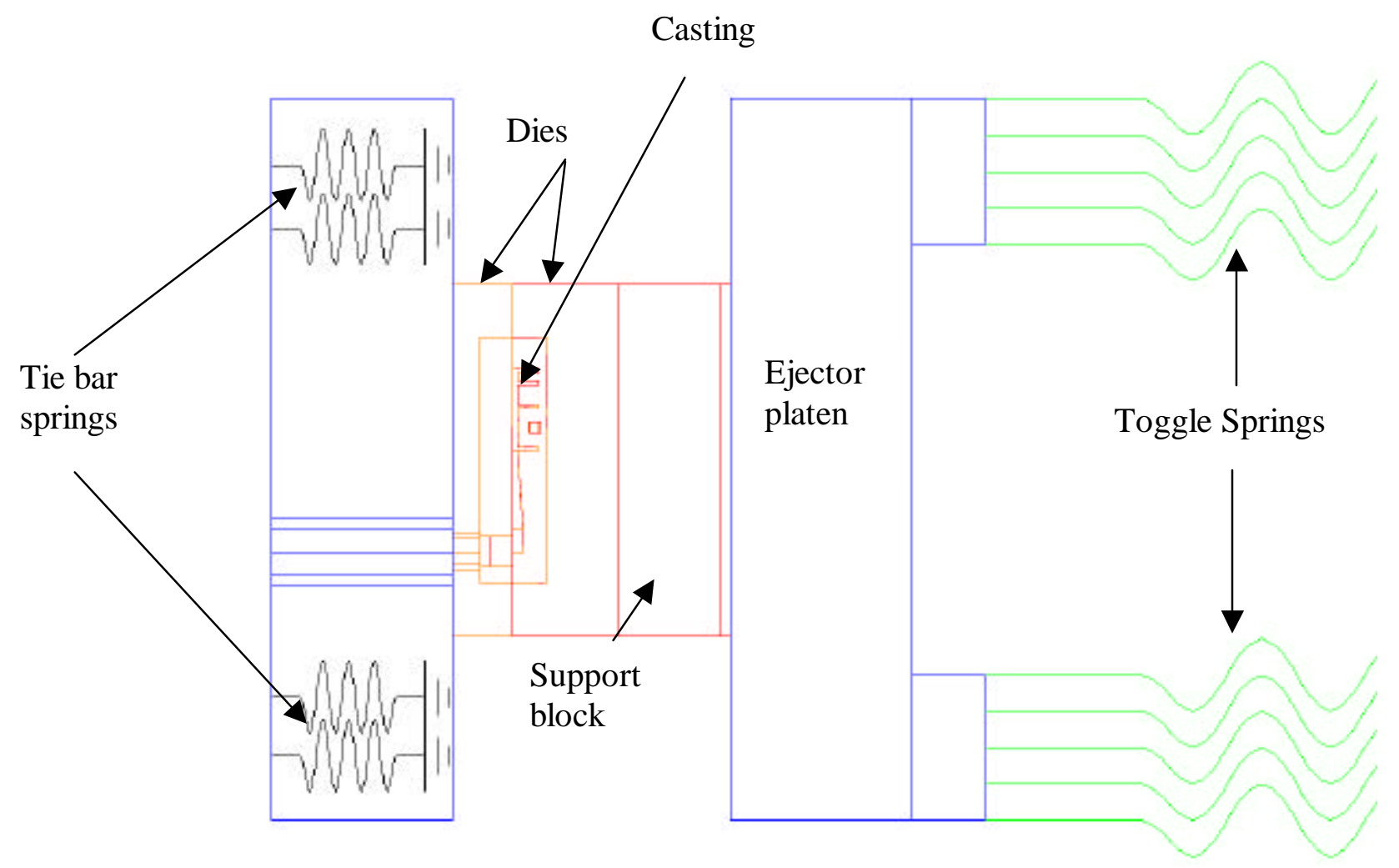

Figure 18 Schematic drawing for the die casting machine model 


\section{Results and Discussion}

\subsection{Part distortion}

Figures 19, $20 \& 21$ show the part distortion using elastic, elasto-plastic and elasto-plastic-creep material models respectively. These material models were used only to represent the casting, while the other machine parts are all assumed elastic. The difference is very clear among the distortion patterns in the three cases. Some of the elements in elasto-plastic and elasto-plastic-creep models showed excess strain. It should be mentioned one more time that we use the creep properties for pure aluminum in our model instead of Al380 creep properties, which are not available. This uncertainty in material properties does not allow the results to be reliable, but the goal here is to develop a methodology that can be used when the correct data are available. Also the material properties can be modified to match the test data when available. In this case we would have an empirical material model.

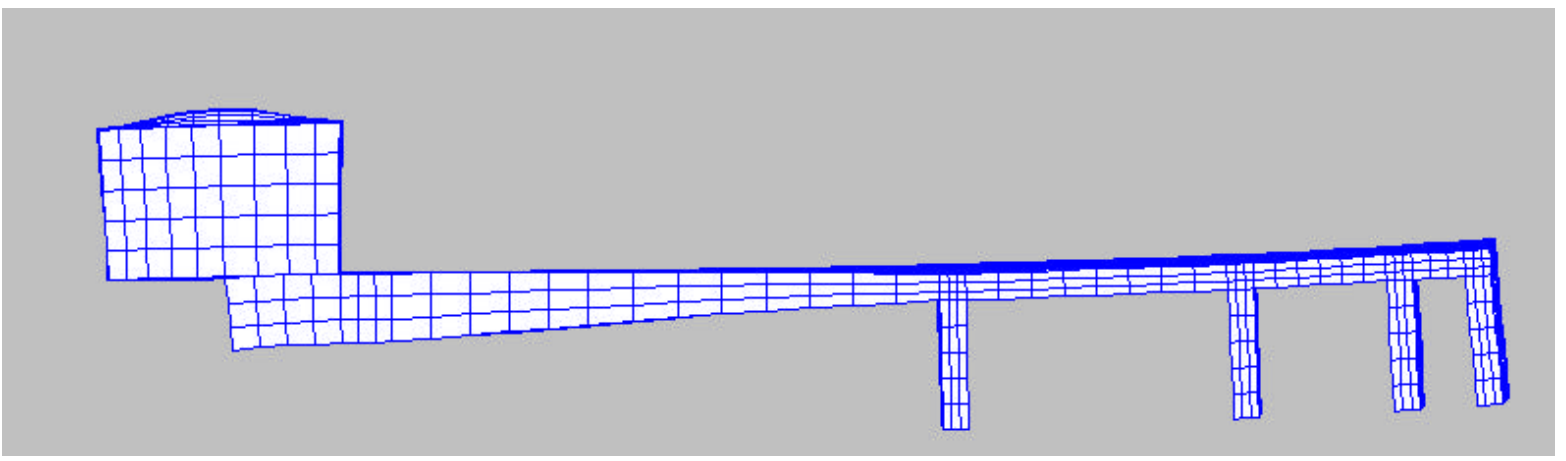

Figure 19 Part distortion - elastic model

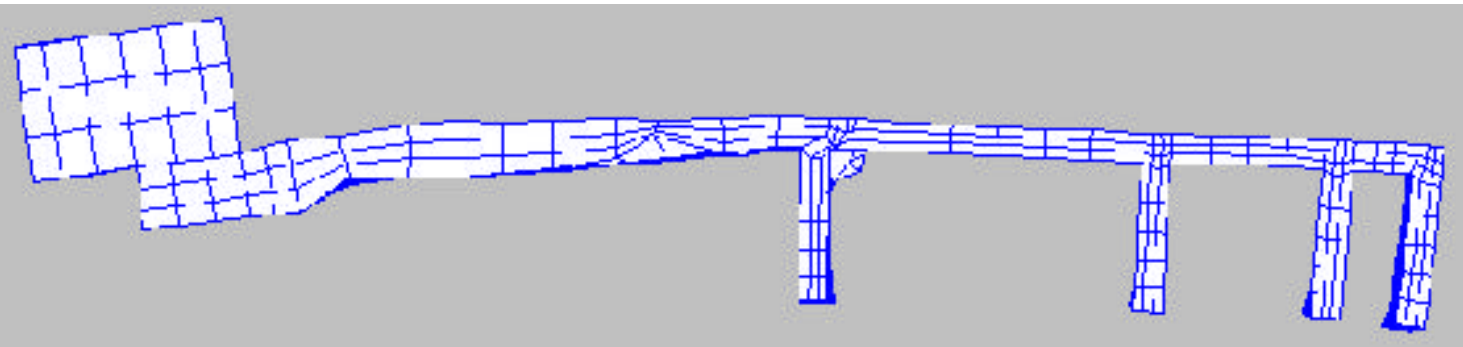

Figure 20 Part distortion - elasto-plastic model 


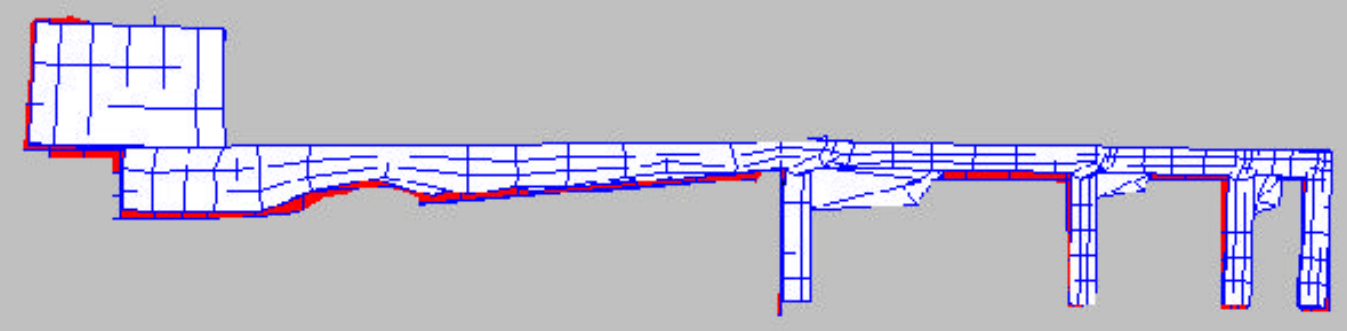

Figure 21 Part distortion - elasto-plastic-creep model

\subsection{Residual Stresses}

Figures $22,23 \& 24$ show the residual stresses in the casting at room temperature for elastic, elasto-plastic and elasto-plastic-creep respectively. The elastic analysis tends to overestimate the residuals stresses, while the other two models allow the casting to relax and lose some of its stresses. The stress results are summarized in Table 4. Figures $25,26 \& 27$ show the residual stresses at ejection for the elastic, elasto-plastic and elastoplastic-creep models respectively. Results at ejection are summarized in Table 5. The stresses tend to be higher at ejection than after complete cooling. This may strengthen the assumption that, the stresses are built in the die because the part is restricted from motion, and then relaxes after the ejection. These results were calculated using constant cavity pressure equals to 10000 Psi. We also used a cavity pressure that decreases from 10000 to 3000Psi within the solidification time. The results showed no significant difference.

\begin{tabular}{|c|c|c|c|c|c|c|c|c|}
\hline \multicolumn{9}{|c|}{ Residual Stresses (MPa) } \\
\hline \multicolumn{2}{|c|}{ Elastic model } & \multicolumn{3}{c|}{$\begin{array}{c}\text { Elasto-plastic } \\
\text { model }\end{array}$} & \multicolumn{3}{c|}{ Elasto-plastic-creep } \\
model \\
\hline Max. & Min. & Ave. & Max. & Min. & Ave. & Max. & Min. & Ave. \\
\hline 950 & 70 & 250 & 130 & 11 & 50 & 32 & 2 & 20 \\
\hline
\end{tabular}

Table 4 Summary of residual stresses in the three material models after complete cooling 


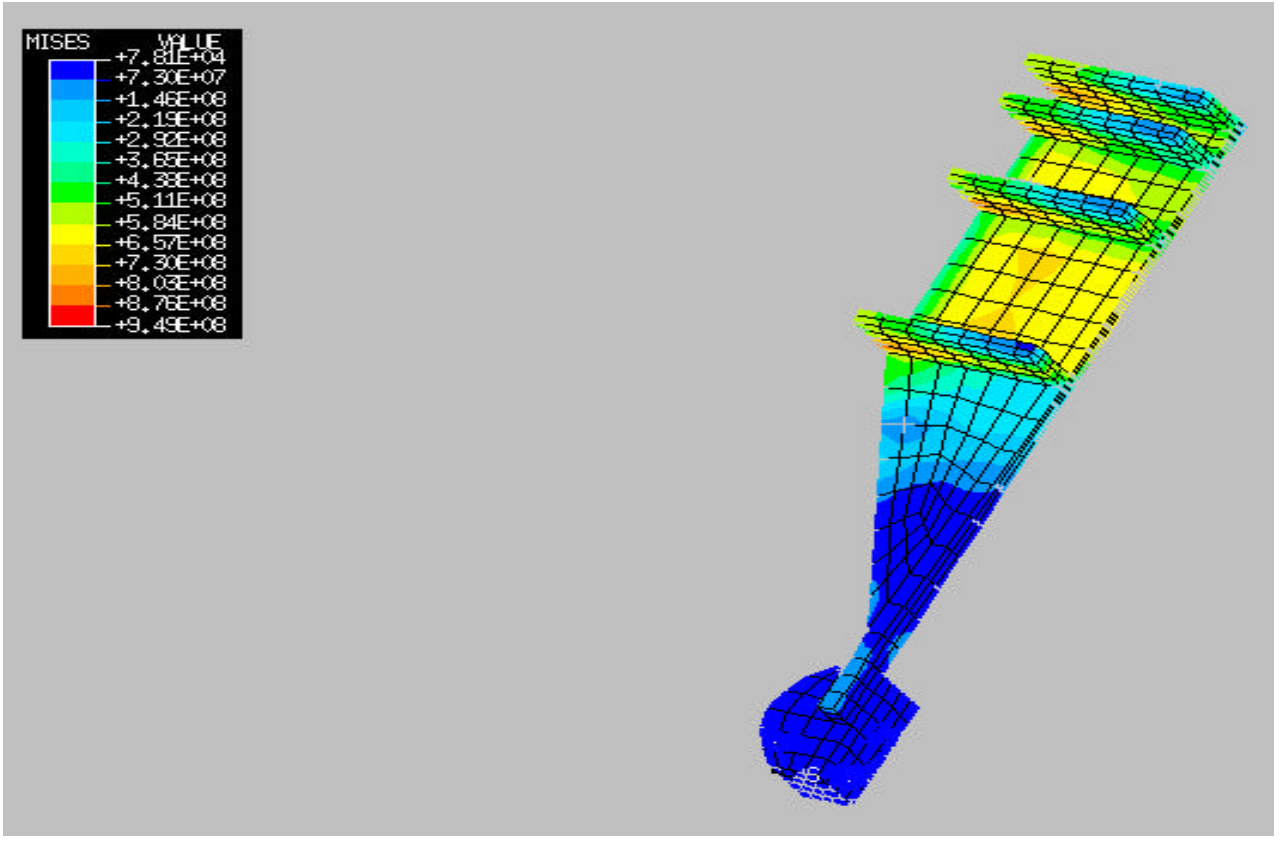

Figure 22 Residual stresses in casting after complete cooling elastic model

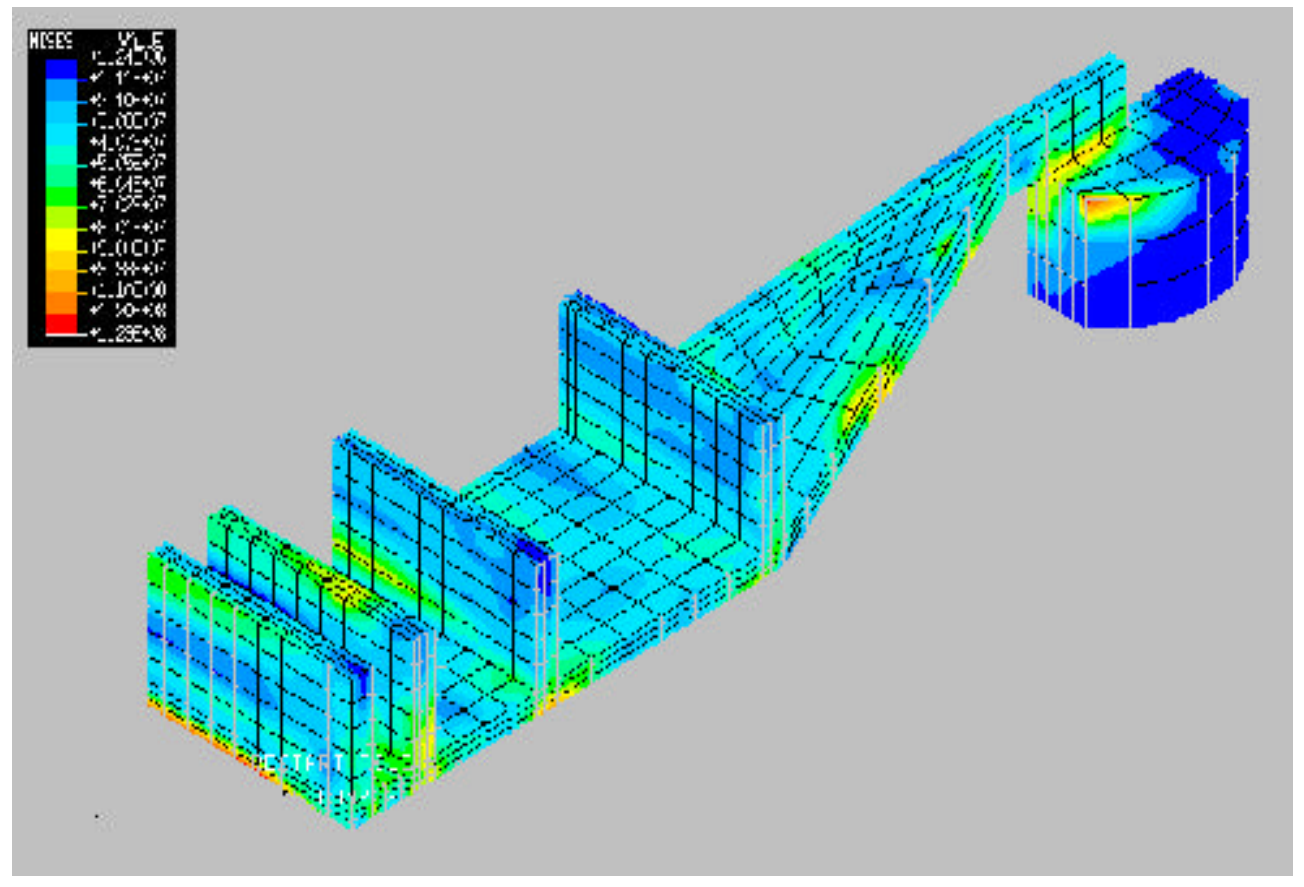

Figure 23 Residual stresses in casting after complete cooling elasto-plastic model 


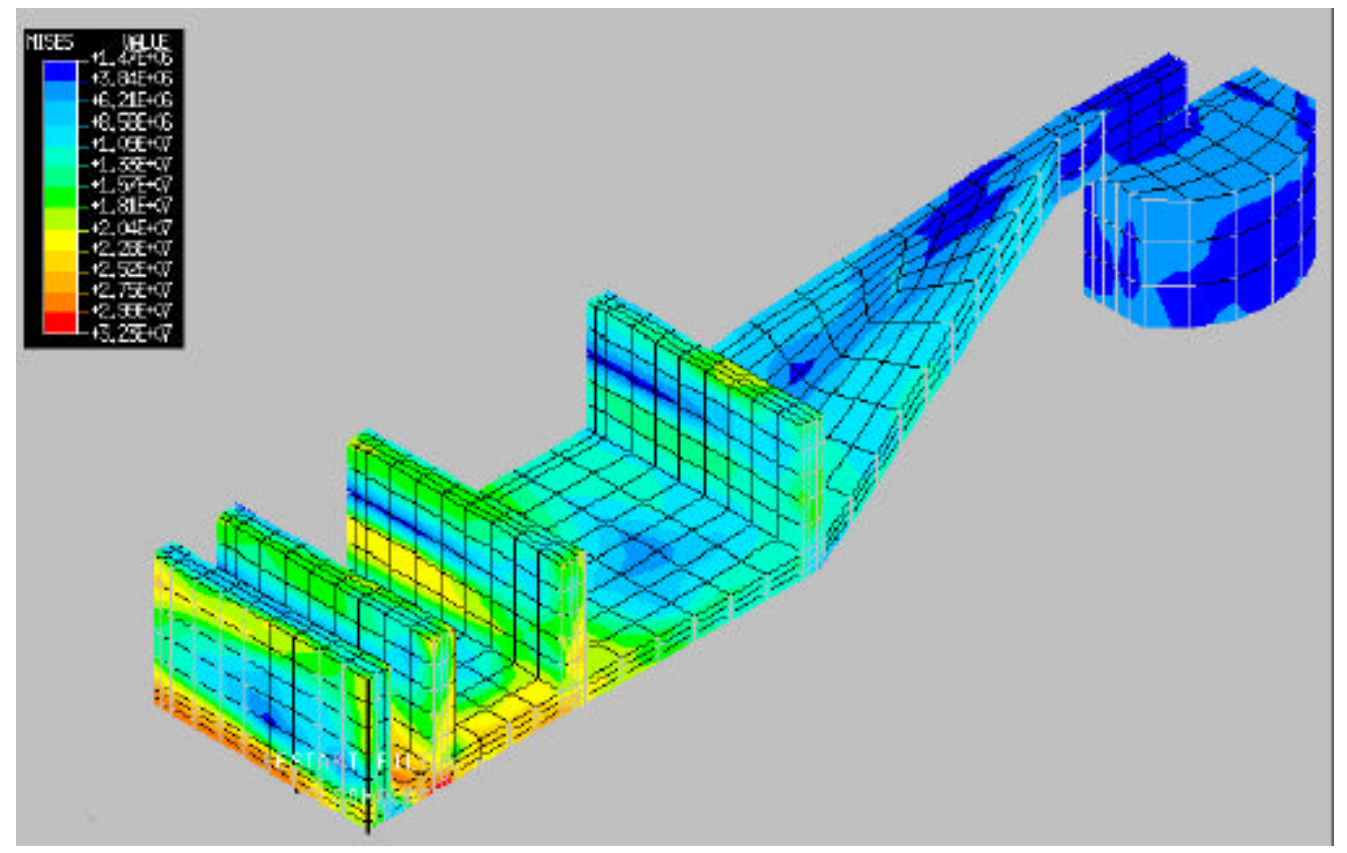

Figure 24 Residual stresses in casting after complete cooling elasto-plastic-creep model

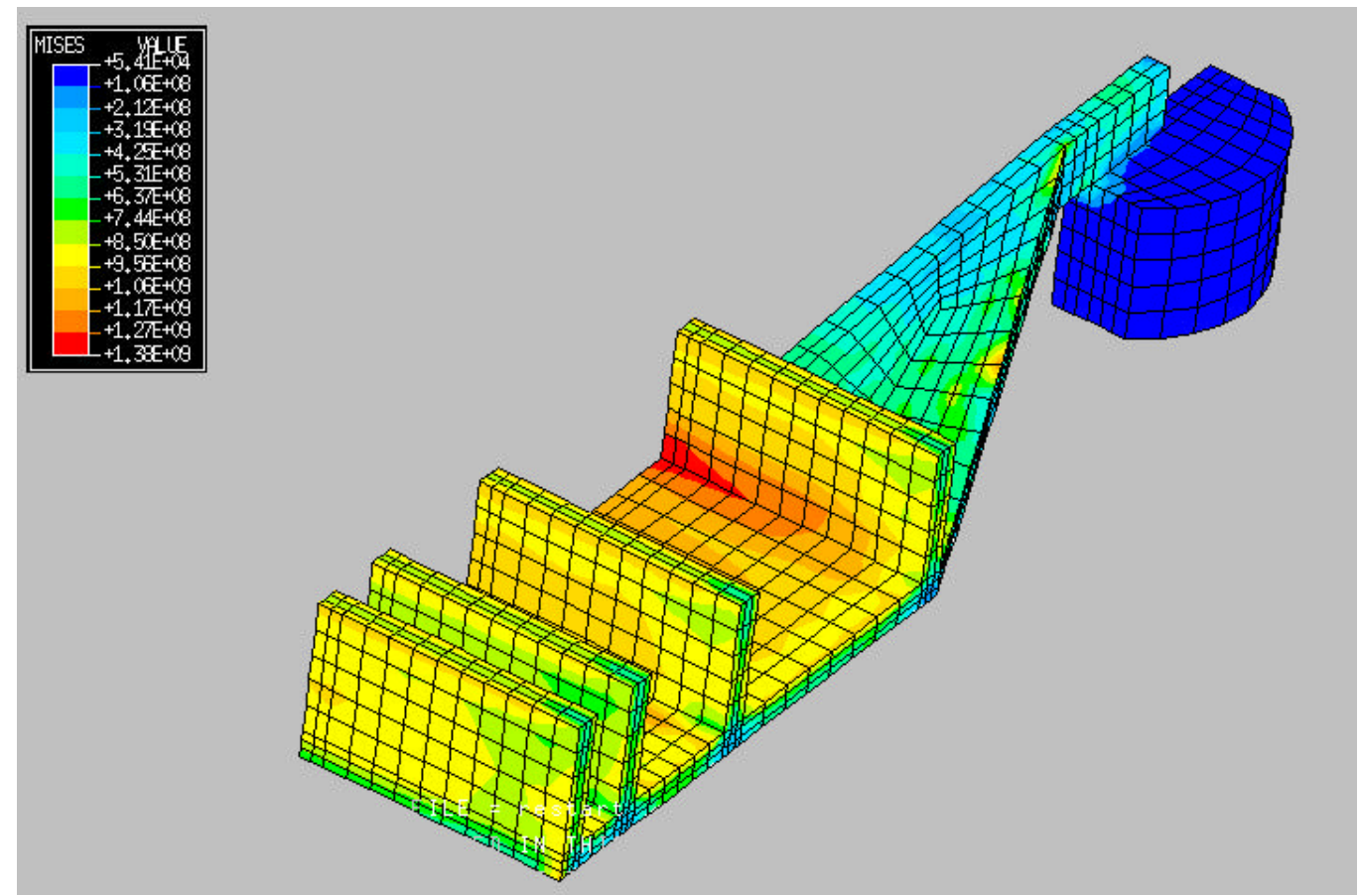

Figure 25 Residual stresses in casting at ejection elastic model 


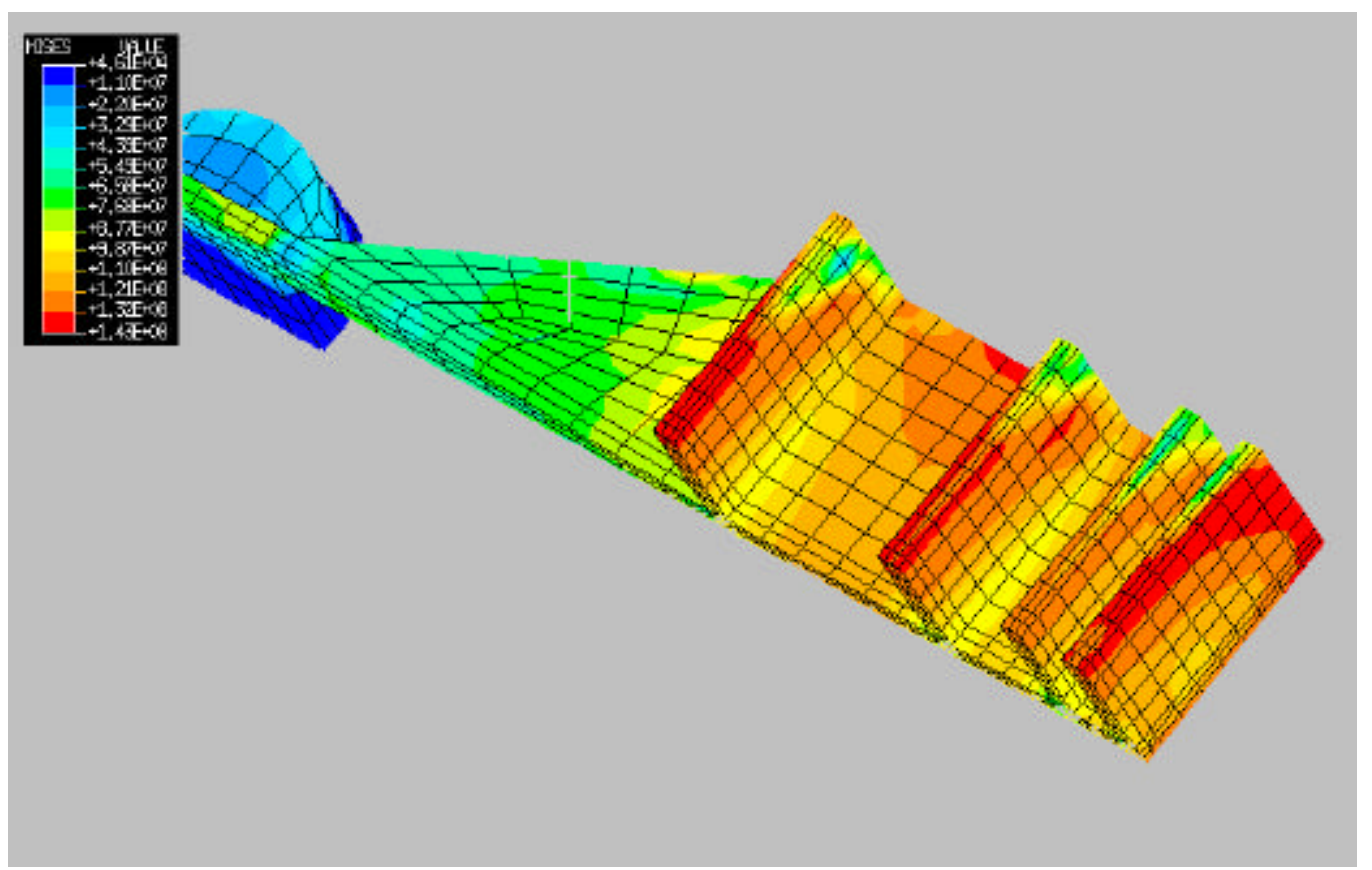

Figure 26 Residual stresses in casting at ejection elasto-plastic model

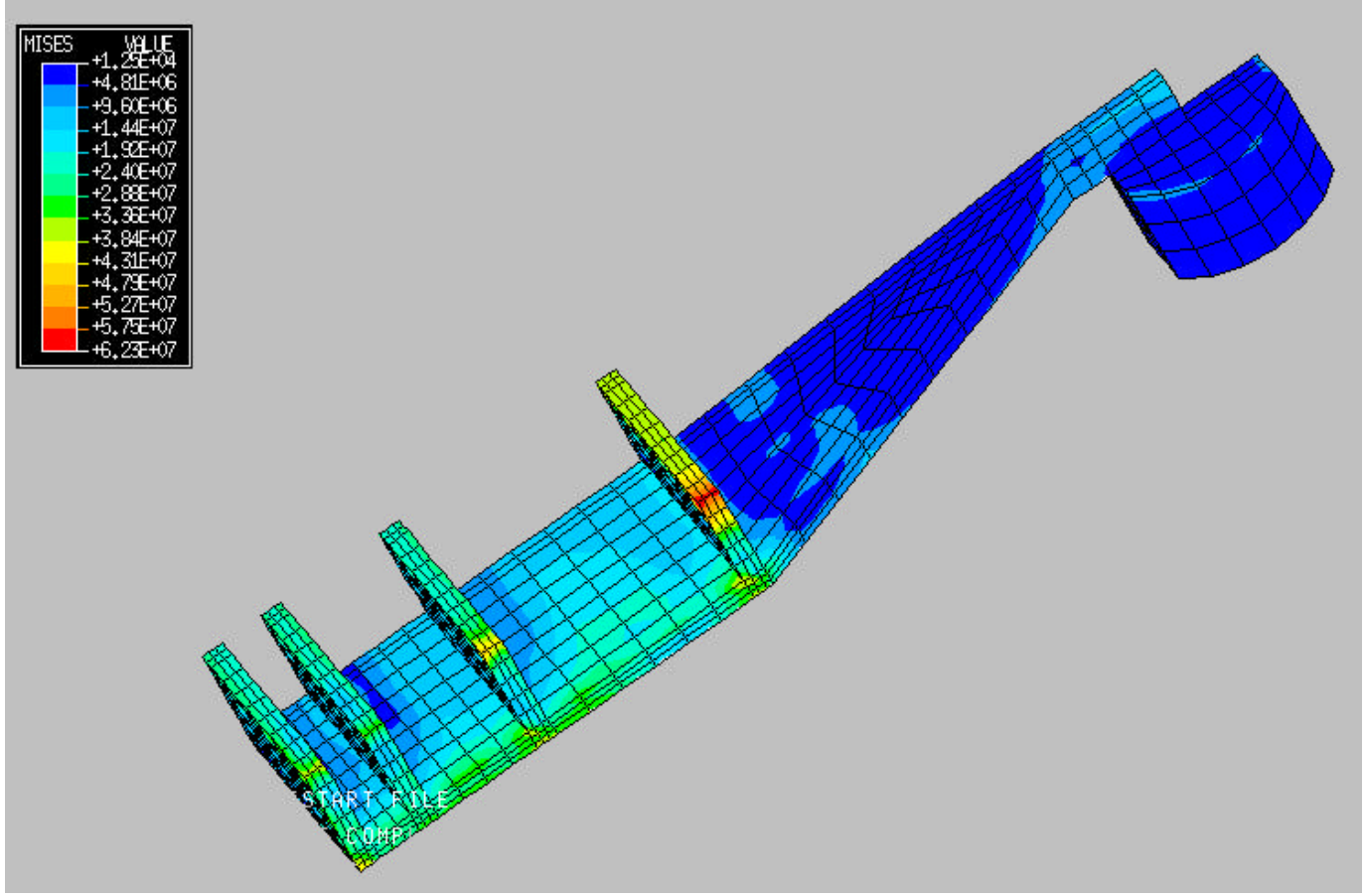

Figure 27 Residual stresses in casting at ejection elasto-plastic-creep model 


\begin{tabular}{|c|c|c|c|c|c|c|c|c|}
\hline \multicolumn{9}{|c|}{ Residual Stresses (MPa) } \\
\hline \multicolumn{2}{|c|}{ Elastic model } & \multicolumn{3}{c|}{$\begin{array}{c}\text { Elasto-plastic } \\
\text { model }\end{array}$} & \multicolumn{3}{c|}{ Elasto-plastic-creep } \\
model
\end{tabular}

Table 5 Summary of residual stresses in the three materials models at ejection

\subsection{Air Gap}

Figures 28 and 29 show the position of air gap formed between the casting and the inserts. The blue color means there is no air gap, while all other colors means there is a gap. The gap is only found at the biscuit and the runner. Accurate results for the gap require applying the hydrostatic pressure correctly. We are not at this point yet, as was explained in the model assumptions. These results are not sensitive to the material model or to the cavity pressure in the model (constant or variable).

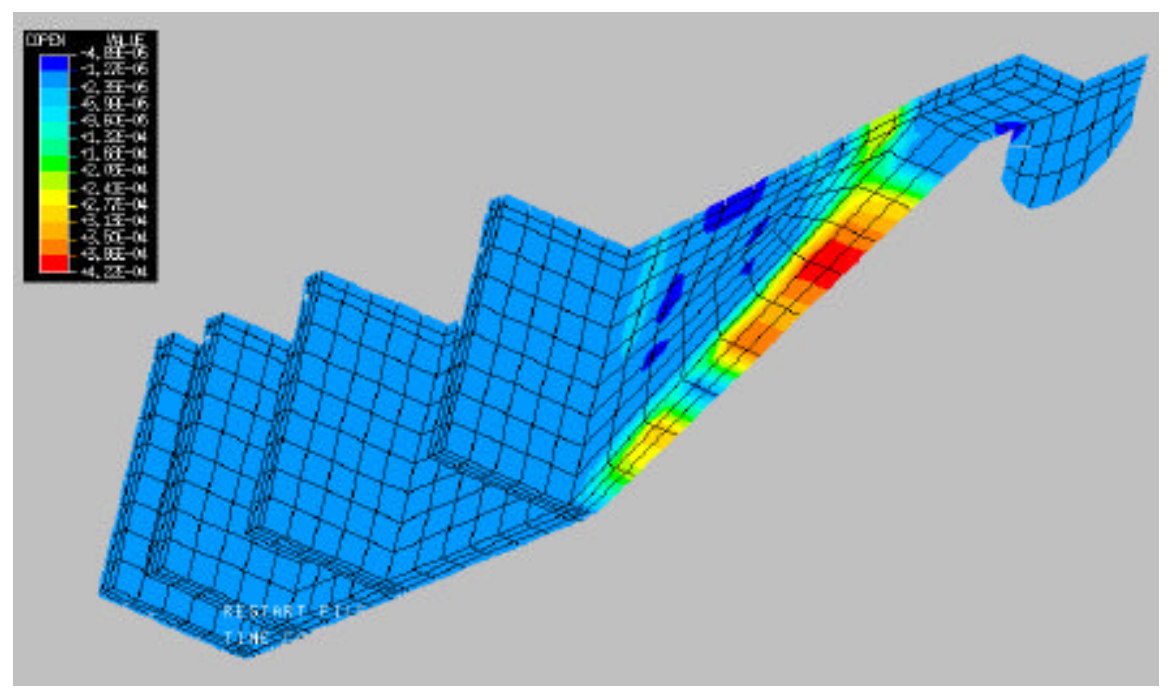

Figure 28 the air gap between the casting and the ejector insert 


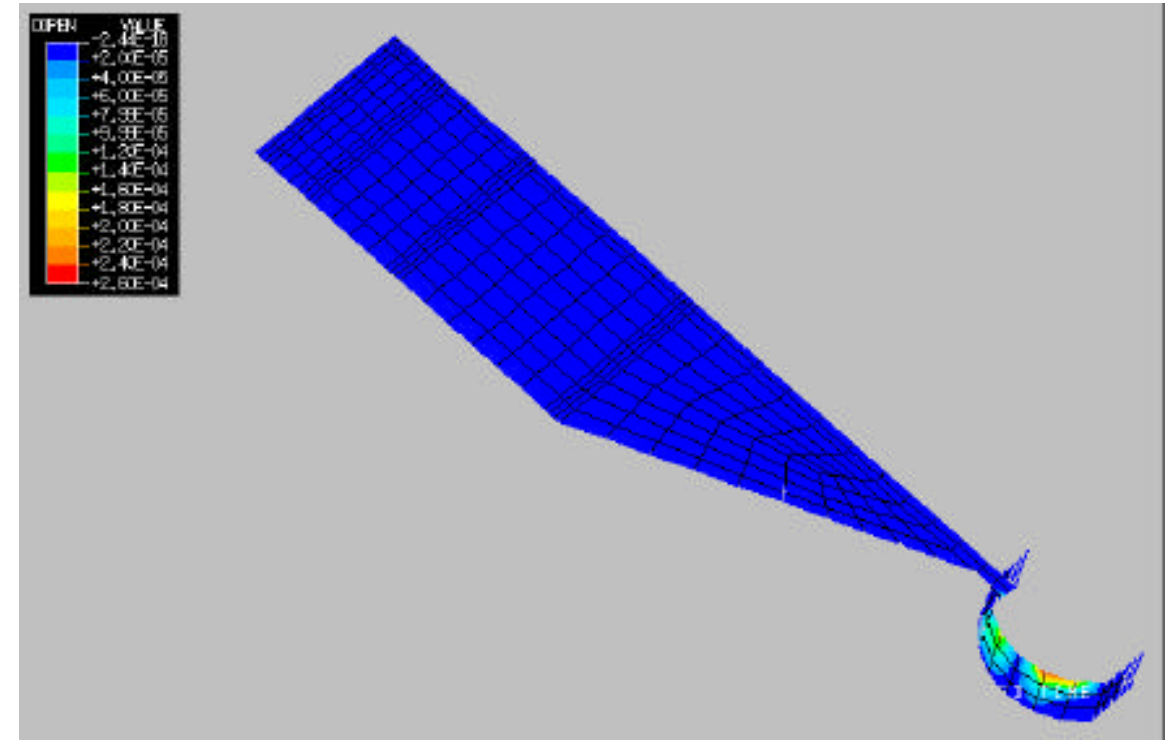

Figure 29 the air gap between the casting and the cover insert

\section{Conclusions}

The goal of this research was to predict the part deformation after complete cooling. A finite element model was built to achieve this goal and several modeling techniques were investigated throughout this research. Some important points were concluded and needs to be stated.

The results from research show the importance of some modeling factors used to represent the die casting process in a simulation. The most important factor is the material model used to describe the casting. In this research three material models were investigated. These are elastic, elasto-plastic and elasto-viscoplastic. The results showed very significant difference in the predicted distortion and residual stresses among the three models. The plasticity and creep allow the casting to relax and release some of its residual stresses. In fact, considering the creep properties in the model results in much higher computational time, and compromise arises between the accuracy and tractability of the model. The decision should be made in particular for each case. 
The research shows also the lack of data for A1380. This includes the creep properties, plasticity properties; yield strength and modulus of elasticity at high temperatures. Using the exact properties in the model is very important in order to get the required accurate results.

The results showed also that the criteria to model some of the machine parts, namely, tie bars and toggle system do not affect the results. The researcher might select the best method to fit his finite element package and to allow results as fast as possible.

There is no way to get reliable results from the simulation unless we can modify our modeling techniques to overcome some of the limitations. The first limitation that we need to overcome is the one-phase simulation. The die casting process is a multi-phase process and we need to consider this in our model. We need to consider the liquid, solid and probably the mushy zone phases. Also we need to compare our simulation results with a well-defined experimental set up.

\section{References}

1- Foundrymen's handbook, the penton publishing Co., Cleveland, O. 1929.

2- Analysis of Casting Defects, The American Foundarymen's Association, Chicago, Illinois, 1947.

3- Anon, "Designing to Avoid Casting Strain.", Casting Engineering \& Foundry World, v 15, n 3, Fall 1983, p40-48.

4- R.N. Parkins, A. Cowan, " The Mechanism of Residual-Stress Formation in Sand Casting.", Journal of the Institute of Metals, Vol.82, 1953-1954, p1-8.

5- Thomas, B. G., "Issues in thermal-mechanical modeling of casting processes", ISIJ International, v 35, n 6, 1995, p 737-743.

6- B.G. Thomas, "Stress Modeling of Casting Processes: An Overview", Modeling of Casting, Welding and Advanced Solidification Processes VI, 1993, p519-534.

7- Drezet, J.M., Plata, M., "Thermomechanical effects during direct chill and electromagnetic casting of aluminum alloys. Part I: experimental investigation", Light 
Metals: Proceedings of Sessions, TMS Annual Meeting [Warrendale, Pennsylvania] 1995, p.931-940.

8- Barone, M. R., Caulk D. A. "Analysis of Liquid Metal Flow in Die Casting", International Journal of Engineering Science, 38, 1279-1302, 2000.

9- J.Campbell, “ Solidification Modeling: Current Limitations and Future Potential.”, Materials Science and Technology, V 7, n 10 Oct 1991, p 885-894.

10- Thomas, B.G., (1995) " Issues in Thermal-Mechanical Modeling of Casting Process" ISIJ International, 35, (6).

11- Y. Nishida, W. Droste, Engler S. " The Air-Gap Formation Process at the CastingMold Interface and the Heat Transfer Mechanism Through the Gap”, Metallurgical Transactions B, V.17B, December 1986, P 833-844.

12. www.matls.com

13- J.C. Lin, J. Righi, “Alloy Influence on Filling, Macroshrinkage, Hot Cracking and Properties in Aluminum Shape Castings.", Automotive Alloys II, The Minerals, Metals and Material Society, 1998, p $45-61$.

14- K.Y. Kim, H. Sakuta, T. Suzuki “ Deformation Analysis of Al-7\%Si-0.3\%Mg Alloy Castings" Modeling of Casting, Welding and Advanced Solidification Processes V, The Minerals, Metals \& Materials Society, 1991.

15- Makhlouf M., Apelian D., Wang L. “ Microstructures and Properties of Aluminum Die Casting Alloys”, NADCA Publication \#215, 1998.

16- “ABAQUS Standard User's Manual”, (1998) Version 5.8, Hibbitt, Karlsson and Sorensen, USA.

17- Shames I.H., and Cozzarelli F.A. (1997) "Elastic and Inelastic Stress Analysis", Taylor \& Francis, 1997. 